Yves Wittwer, Robert Eichler*, Dominik Herrmann and Andreas Türler

\title{
The influence of chemical parameters on the in- situ metal carbonyl complex formation studied with the fast on-line reaction apparatus (FORA)
}

https://doi.org/10.1515/ract-2020-0031

Received April 2, 2020; accepted January 23, 2021;

published online February 15, 2021

\begin{abstract}
A new setup named Fast On-line Reaction Apparatus (FORA) is presented which allows for the efficient investigation and optimization of metal carbonyl complex (MCC) formation reactions under various reaction conditions. The setup contains a ${ }^{252} \mathrm{Cf}$-source producing short-lived Mo, Tc, $\mathrm{Ru}$ and $\mathrm{Rh}$ isotopes at a rate of a few atoms per second by its 3\% spontaneous fission decay branch. Those atoms are transformed within FORA in-situ into volatile metal carbonyl complexes (MCCs) by using CO-containing carrier gases. Here, the design, operation and performance of FORA is discussed, revealing it as a suitable setup for performing single-atom chemistry studies. The influence of various gas-additives, such as $\mathrm{CO}_{2}, \mathrm{CH}_{4}, \mathrm{H}_{2}, \mathrm{Ar}, \mathrm{O}_{2}, \mathrm{H}_{2} \mathrm{O}$ and ambient air, on the formation and transport of MCCs was investigated. $\mathrm{O}_{2}, \mathrm{H}_{2} \mathrm{O}$ and air were found to harm the formation and transport of MCCs in FORA, with $\mathrm{H}_{2} \mathrm{O}$ being the most severe. An exception is Tc, for which about 130 ppmv of $\mathrm{H}_{2} \mathrm{O}$ caused an increased production and transport of volatile compounds. The other gas-additives were not influencing the formation and transport efficiency of MCCs. Using an older setup called Miss Piggy based on a similar working principle as FORA, it was additionally investigated if gas-additives are mostly affecting the formation or only the transport stability of MCCs. It was found that mostly formation is impacted, as MCCs appear to be much less sensitive to reacting with gasadditives in comparison to the bare Mo, Tc, $\mathrm{Ru}$ and $\mathrm{Rh}$ atoms.
\end{abstract}

Keywords: carbonyl complexes; single atom chemistry; transition metals.

\footnotetext{
*Corresponding author: Robert Eichler, Paul Scherrer Institute, Villigen, Switzerland, E-mail: robert.eichler@psi.ch

Yves Wittwer, Paul Scherrer Institute, Villigen, Switzerland; and University of Bern, Bern, Switzerland

Dominik Herrmann, Paul Scherrer Institute, Villigen, Switzerland

Andreas Türler, University of Bern, Bern, Switzerland
}

\section{Introduction}

Metal carbonyl complexes (MCCs) and their derivatives are an important class of substances in modern chemistry. Their relevance includes being reagents and catalysts in synthesis $[1,2]$, and potential pharmaceuticals [3-6]. In macrochemistry, MCCs are usually synthesized under high pressures of CO-gas and elevated temperatures from either a metal powder or metal compound. Reduction agents or catalysts are often employed, whereas only a few MCCs, like $\mathrm{Ni}(\mathrm{CO})_{4}$ and $\mathrm{Fe}(\mathrm{CO})_{5}$, can be synthesized by simply combining the corresponding metal powders with $\mathrm{CO}[1,7,8]$. It was recently discovered that MCCs can be synthesized at room temperature and ambient pressure under single-atom chemistry conditions, a production path also relevant for the formation of volatile carbonyl complexes in radioactive wastes [9]. If single atoms of group 6 up to group 9 transition metals are emitted into CO-containing atmospheres, they were found to form in-situ volatile MCCs [10-17]. This method enables a number of potential applications, i.e., the possible generation of yet unavailable radioactive beams of refractory elements in accelerators $[18,19]$ or the chemical investigation of transactinides (elements with $Z \geq 104$ ) which are not volatile in their elemental state [10-17, 20-22].

Recently, the first successful synthesis of $\mathrm{Sg}(\mathrm{CO})_{6}$ paved the way for the investigation of various transactinides (TAs) in form of their corresponding MCCs [16]. Chemical investigations of TAs are challenging due to low production rates, ranging from a few atoms per minute to atoms per week or even per month, and short half-lives. Additionally, a large number of side products are formed during the nuclear fusion reaction synthesis of TAs. Due to all these reasons, highly efficient separation apparatuses are desirable. The chemistry of TAs is heavily influenced by relativistic effects, potentially leading to unexpected behaviors and compound properties [20-25]. The use of MCCs theoretically allows the chemical investigation of $\mathrm{Sg}, \mathrm{Bh}$, Hs and Mt since all elements belonging to group 6 up to group 9 in the periodic table are known or expected to form MCCs $[20,25]$. MCCs are volatile enough to be transported in the gas-phase, allowing for fast and efficient experiments [10-13, 16, 17, 21, 26, 27]. 
Experiments targeted at investigating and comparing the chemistry of group 6 MCCs were suffering so far from low chemical and transport yields, ranging from about $40 \%$ for $\mathrm{Mo}(\mathrm{CO})_{6}$ to $10-20 \%$ for $\mathrm{W}(\mathrm{CO})_{6}$ and $5 \%$ for $\mathrm{Sg}(\mathrm{CO})_{6}$ [26]. This caused serious doubts about investigating heavier TAs in form of MCCs in general. This work is intended to systematically investigate experimental parameters influencing the overall synthesis and transport yield of MCCs in single-atom chemistry experiments.

\section{Experimental}

\subsection{The FORA-setup}

To allow an efficient investigation of the MCC-formation reaction for various elements under single-atom chemistry conditions, the FORA system located at the University of Bern, Switzerland was constructed. The system is designed to mimic an actual accelerator-based apparatus suitable to investigate TAs. It is schematically shown in Figure 1.

In contrast to the previously described Miss Piggy setup [28] used in MCC investigations [13], FORA is constructed to operate as a gasloop. During operation, FORA is filled with a pre-defined process gas containing CO up to a certain pressure and stable gas flow. In the standard-configuration, up to two gases can be mixed using two MassFlow-Controllers (MFCs), MFC1 and MFC2 in Figure 1. After initial mixing, the process gas travels through a Sicapent ${ }^{\mathrm{TM}}$ cartridge avoiding a potential contamination of the entire loop with traces of water from the introduced bottled gas. During operation, the process gas is constantly circulating through the system, which can be theoretically operated for an unlimited time without the need to add additional CO. The gas flow is established by a helium-tight metal bellows pump.

Since FORA is designed in a modular way with connections based on Swagelok ${ }^{\circledR}$, it can be modified to allow for various types of investigations. In its standard-configuration, it contains a purification setup containing up to two columns. The use of purification columns is dependent on the experiment performed and they can therefore, be easily exchanged or entirely bypassed.

Pressure, dew point and gas flow are continuously monitored. Therefore, a pressure sensor and a hygrometer are located directly in front of the reaction chamber and connected to a LabVIEW based recording program. The gas flow is controlled and measured using an additional MFC (MFC3 in Figure 1). An analog Volume-Flow-Meter (VFM in Figure 1) is installed directly after MFC3 to have a second, qualitative control of the gas flow. All MFCs were tested using a Defender 530+-device (from MesaLabs) prior to usage.

The initial synthesis of MCCs is taking place in the reaction chamber (labeled “"252 Cf-Source” in Figure 1). A 3D-illustration and cross section of the reaction chamber is shown in Figure 2.

In order to perform chemical investigations under single-atom chemistry conditions and mimic the conditions in an actual accelerator based setup suitable for TA investigations (see e.g. [16]), a ${ }^{252} \mathrm{Cf}$ source prepared in 1996 [28] is used. ${ }^{252} \mathrm{Cf}$ decays with a half-life of 2.645 years via $\alpha$-particle emission, but has a branching to spontaneous fission decay of $3 \%$ which is of interest for this study [29]. Based on the initial mass of $4 \mu \mathrm{g}^{252} \mathrm{Cf}$ a remaining amount of about $100 \mathrm{ng}$ can be estimated for the time of these studies. The material is deposited on a round Pt-plate with a diameter of $6 \mathrm{~mm}$. The source is covered by a

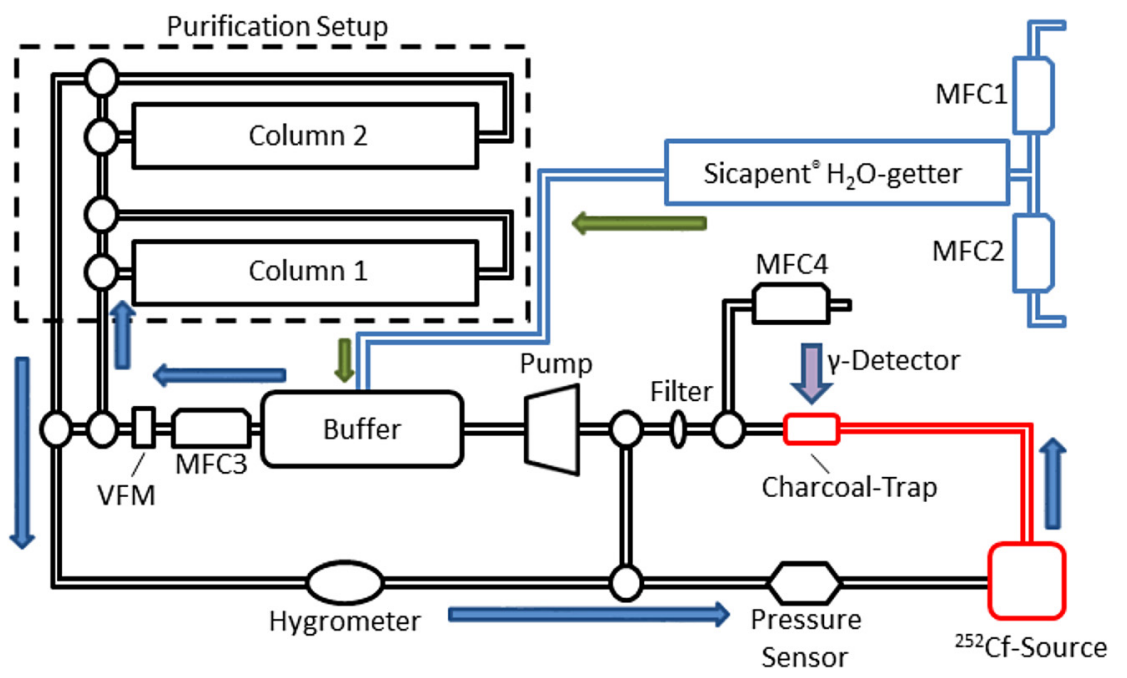

Figure 1: The FORA-setup used for the investigations of MCC-chemistry under single-atom conditions. The black and blue parts were made from stainless steel, the red ones from PFA-TEFLON ${ }^{\circledR}$. The process gas is flowing through the black and red parts in counterclockwise direction. The blue part is only used for filling the system with fresh process gas. The system contains a purification unit consisting of easily exchangeable purification columns which can all be bypassed. The Sicapent ${ }^{\mathrm{TM}}$ column at the gas entrance was always used, Column 1 and 2 were adapted to the performed experiment. The blue arrows mark the gas flow direction during regular operation, the green ones during filling. VFM stands for Volume-Flow-Meter, MFC for Mass-Flow-Controller. The circles are representing three-way vales for adjusting the gas flow path through the system. MFC1 and MFC2 are used to prepare gas mixtures containing CO. MFC 3 measures the real gas flow in the loop and MFC4 is used to add artificial contaminants to the process gas. 


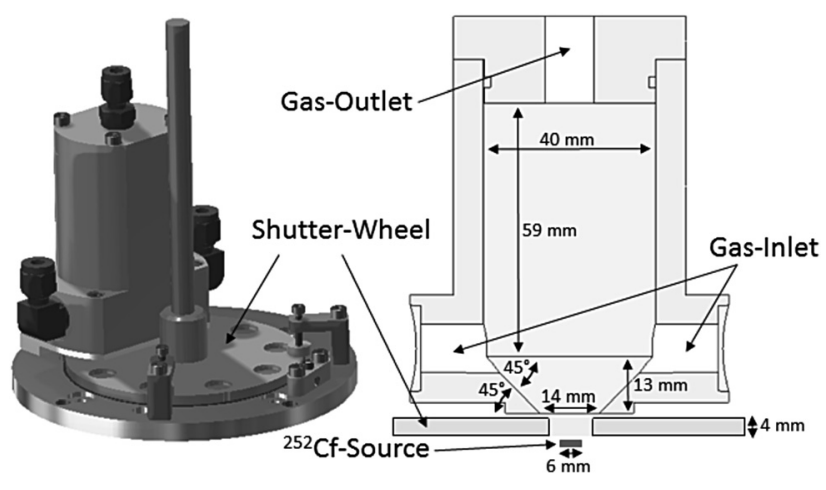

Figure 2: The reaction chamber used in the FORA-setup. Left: 3D-illustration including the wheel located between the reaction chamber and the ${ }^{252} \mathrm{Cf}$-source. Note some of the holes inside the wheel can be occupied with degrader foils of various thicknesses if desired (not used here). One hole is entirely closed to act as a source shutter. Right: Cross section through the reaction chamber. Gasinlets and outlet are indicated as well as dimensions.

$6 \mu \mathrm{m}$ thick aluminum-foil to avoid contamination of the setup. The reaction chamber is located above the source having an almost cylindrical shape (see Figure 2). Between the chamber and the ${ }^{252} \mathrm{Cf}-$ source, a shutter wheel is mounted used to open and close the reaction chamber towards the source. The entire reaction chamber is enclosed inside a steel-containment. The steel-containment is filled with leaking process gas during operation and is well sealed (see Figure 3). The in-going as well as out-going tubes are passed through the walls of the steel containment using Swagelok ${ }^{\circledR}$ feed through.

The reaction chamber is connected to a $12 \mathrm{~cm}$ long charcoal trap by a $2 \mathrm{~m}$ long PFA-TEFLON ${ }^{\circledR}$ tube (inner diameter $2 \mathrm{~mm}$ ), which is surrounded by a steel cladding-tube, which can be separately evacuated to prevent contaminants diffusion through the thin PFA-TEFLON ${ }^{\circledR}$ walls. A filter was installed behind the charcoal trap during operation to avoid accidental contamination of the system with charcoal dust. The charcoal trap can be easily exchanged. Quarz-wool plugs were used to keep the charcoal in place and assure a well defined geometry. Prior to being mounted into the FORA-setup, the charcoal traps were heated out for 10 min at $150-200{ }^{\circ} \mathrm{C}$ with a $\mathrm{N}_{2}$ flow of $100 \mathrm{smL} / \mathrm{min}$ applied.

All surfaces potentially in contact with radioactive MCCs are made from PFA-TEFLON ${ }^{\circledR}$, including the reaction chamber, tubes, fed throughs and valves, to minimize adsorption and potential decomposition losses. The wheel used for opening and closing the reaction chamber as well as the ${ }^{252} \mathrm{Cf}$-holder are made from aluminum. The rest of the system is constructed from stainless steel (316S). Valves made from PFA-TEFLON ${ }^{\circledR}$ were purchased from EM-Technik GmbH. The other valves (Swagelok ${ }^{\circledR}$ ) as well as steel tubes were purchased from Arbor, Switzerland. PFA-TEFLON ${ }^{\circledR}$ tubes/capillaries were provided by Rotima AG. The metal bellows pump used (MB158) was provided by Senior Aerospace. All MFCs (8580S) were made by Brooks. Concerning monitoring, the pressure sensor (MAN-SD3S-A) was provided by Kobold, the hygrometer (Easidew Transmitter Range: $-100 /+20$ ) by Michell Instruments and the VFM (Typ V100) was manufactured by Vögtlin. A National Instruments AID was used to connect pressure sensor and hygrometer with a LabVIEW (V14.0.1) based recording program. The charcoal was obtained from Sigma-Aldrich. CO (99.997\%), $\mathrm{CO}_{2}$ (99.998\%), $\mathrm{CH}_{4}$ (99.95\%), $\mathrm{H}_{2}(99.999 \%), \mathrm{O}_{2}(99.999 \%)$ and $\operatorname{Ar}(99.999 \%)$ were all purchased from Carbagas.

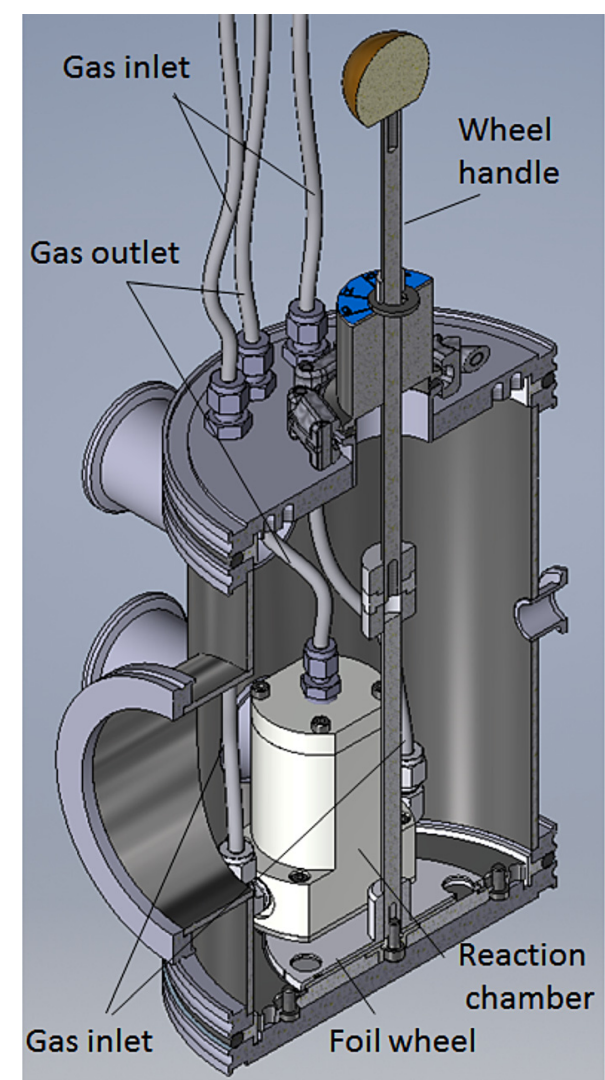

Figure 3: Cross section through the steel-containment containing the reaction chamber of FORA. The steel-containment serves two purposes. Firstly, it is a safety measure to avoid the release of $\mathrm{CO}$ and secondly, it avoids the accidental introduction of air into the system during operation. The steel-containment is evacuated and filled with process gas prior to each measurement series.

\subsection{FORA-operation}

To initiate the synthesis of MCCs, the shutter wheel is turned to open the reaction chamber for incoming fission products recoiling from the ${ }^{252} \mathrm{Cf}$-source. Amongst other fission products some short-lived isotopes of Mo, Tc, Ru and Rh are produced by the spontaneous fission of ${ }^{252} \mathrm{Cf}$ and are thermalized in the process gas. In CO-containing atmospheres volatile compounds from Mo, Tc, $\mathrm{Ru}$ and $\mathrm{Rh}$ are formed. These are flushed out of the reaction chamber by the carrier gas flow. Subsequently, they travel along the $2 \mathrm{~m}$ long PFA-TEFLON ${ }^{\circledR}$ tube until they reach the charcoal trap. Here, they are trapped due to the large surface of the charcoal, adsorbing long enough to decay. A HPGe $y$-spectrometer directly pointed at the charcoal trap is used to detect and quantify the trapped fission products. Therefore, a dedicated data acquisition system based on Canberra's Genie2 $\mathrm{k}^{\circledR}$ software is used. The area of the detected $y$-peaks corresponding to each isotope is determined to quantify amount and finally overall chemical and transport yield for the associated volatile species. A consistent measurement geometry between charcoal trap and HPGe-detector was always established. The entire detection setup was shielded using a layer of lead-blocks inside lined by a layer of copper-plates to suppress the X-rays from the lead shielding. 
Since Mo, Tc, Ru and $\mathrm{Rh}$ are not volatile in their elemental state, they must undergo chemical reactions to form compounds volatile enough to be transported by the gas-stream. It was shown in the past, that those volatile compounds formed under $\mathrm{CO}$-atmosphere are most probably MCCs [11-13, 16, 26, 27]. The volatile species formed in the FORA-system are therefore assumed to be $\mathrm{Mo}(\mathrm{CO})_{6}, \mathrm{Tc}(\mathrm{CO})_{n}, \mathrm{Ru}(\mathrm{CO})_{5}$ and $\mathrm{Rh}(\mathrm{CO})_{m}$ if not suggested otherwise by our results. In macroscopic chemistry, Tc and Rh are forming dinuclear complexes. However, since the experiments using FORA were performed using single-atom chemistry conditions, the dilution of atoms is too high to allow for the formation of such polynuclear complexes. It is therefore not clear yet, what carbonyl-species are exactly formed for Tc and $\mathrm{Rh}[10,11,26,27]$. For group 7 elements, the formation of hydrides (e.g. $\mathrm{TcH}(\mathrm{CO})_{5}$ ) was recently suggested by reaction with $\mathrm{H}_{2} \mathrm{O}$-impurities present in the process gas [30].

${ }^{104} \mathrm{Mo},{ }^{107} \mathrm{Tc},{ }^{110} \mathrm{Ru}$ and ${ }^{111} \mathrm{Rh}$ where selected as best representatives available for elements of groups 6-9 (see Figure 4 and Table 1). The chosen isotopes must fulfill a number of conditions. They need to be long-lived enough to reach the charcoal trap; they need to show strong and non-interfering $\gamma$-lines; they have to be produced in decent quantities during ${ }^{252} \mathrm{Cf}$ spontaneous fission and they are not allowed to have long-lived volatile or carbonyl-forming precursors (see Figure 4). The transport time of MCCs formed in the FORA reaction chamber to the charcoal trap at a gas flow of $1000 \mathrm{~mL} / \mathrm{min}$ can be estimated to be about $5.5 \mathrm{~s}$, with about $4 \mathrm{~s}$ required to leave the reaction chamber and $1.5 \mathrm{~s}$ required to travel through the pipes connecting the chamber with the charcoal trap. The estimation is based on the traversed volume divided through the chosen gas flow rate. For ${ }^{104} \mathrm{Mo}$ interfering effects from precursors can be neglected since $\mathrm{Nb}$ is not known to form volatile MCCs. For ${ }^{110} \mathrm{Ru}$, precursor effects can be ignored as well since despite the precursors ${ }^{110} \mathrm{Mo}$ and ${ }^{110} \mathrm{Tc}$ being able to form volatile MCCs, the fission yields and half-lives of those isotopes are too low to allow for an efficient transport to the charcoal trap. For ${ }^{107} \mathrm{Tc}$ and ${ }^{111} \mathrm{Rh}$ on the other hand, a contribution from the precursors can not be excluded with absolute certainty. In the case of ${ }^{107} \mathrm{Tc}$, the precursor ${ }^{107} \mathrm{Mo}$ has a much lower half-life and is produced in smaller quantities by ${ }^{252} \mathrm{Cf}$ fission in comparison with ${ }^{107} \mathrm{Tc}$. However, it can not be neglected that if the chemical yield for MCCs formed by ${ }^{107} \mathrm{Tc}$ becomes much lower than the yield for ${ }^{107} \mathrm{Mo}(\mathrm{CO})_{6}$, the observed behavior associated with ${ }^{107} \mathrm{Tc}$ starts to reflect the one of ${ }^{107} \mathrm{Mo}$. The same is true for ${ }^{111} \mathrm{Rh}$. While the precursors ${ }^{111} \mathrm{Mo}$ and ${ }^{111} \mathrm{Tc}$ can be neglected, the fission yield and half-life of ${ }^{111} \mathrm{Ru}$, despite being lower than the ones of ${ }^{111} \mathrm{Rh}$, they are still high enough to allow interference with the apparent behavior of ${ }^{111} \mathrm{Rh}$ if the chemical yields for the formation of MCCs from Rh are much lower than the ones for the formation of ${ }^{111} \mathrm{Ru}(\mathrm{CO})_{5}$.

In preparatory studies, $y$-spectra recorded with FORA corresponding to well optimized and non-optimized yields for the formation of MCCs were investigated for peaks corresponding to ${ }^{107} \mathrm{Mo}$ and ${ }^{111} \mathrm{Ru}$. The investigated spectra did not indicate the presence of large amounts of ${ }^{107} \mathrm{Mo}$. For ${ }^{111} \mathrm{Ru}$ on the other hand, a clear identification is more difficult due to interferences with other volatile fission products, making a clear statement concerning its appearance more difficult. The obtained different dependencies of ${ }^{110} \mathrm{Ru}$ and ${ }^{111} \mathrm{Rh}$ in our parameter studies indicate that the precursor effects of ${ }^{111} \mathrm{Ru}$ are not dominant for the observation of the ${ }^{111} \mathrm{Rh}$ behavior. It can be concluded that the observed data do not indicate a significant impact of precursor effects.

\subsection{Determination of absolute yields}

The data shown in this presentation were all normalized as described in the caption of each figure. The conversion of the obtained data points into absolute yields was attempted. For this purpose, long-lived fission products were collected using catcher foils at the fission product entrance into the FORA chamber. The accumulated activity was measured by $y$-spectroscopy. From the obtained activities, the

Table 1: Isotopes investigated during this study with their associated $\gamma$-lines and corresponding $\gamma$-branching ratios. For ${ }^{104} \mathrm{Mo}$, the two peaks were not properly resolved and therefore integrated together. Data were taken from Nucleonica [29].

\begin{tabular}{lrr}
\hline Nuclide & Y-energy & Y-branching \\
\hline${ }^{104} \mathrm{Mo}$ & $68.8 \mathrm{keV} / 69.7 \mathrm{keV}$ & $55 \% / 18 \%$ \\
${ }^{107} \mathrm{Tc}$ & $102.7 \mathrm{keV}$ & $21 \%$ \\
${ }^{110} \mathrm{Ru}$ & $112.2 \mathrm{keV}$ & $25 \%$ \\
${ }^{111} \mathrm{Rh}$ & $275.4 \mathrm{keV}$ & $71.9 \%$ \\
\hline
\end{tabular}

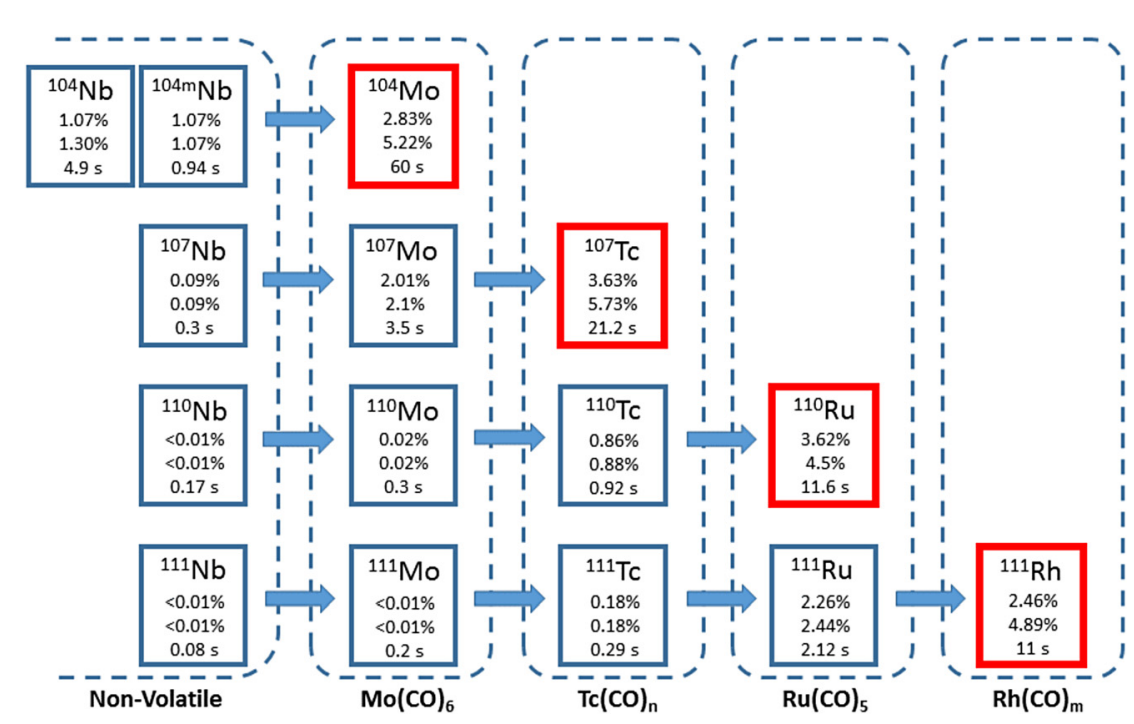

Figure 4: ${ }^{252} \mathrm{Cf}$ fission products and genetically linked $\beta^{-}$-decay chains relevant for this study. The nuclides marked in red were measured. The numbers below each isotope (from top to bottom) correspond to its direct fission yield, cumulative fission yield and half-life, respectively. None of the isotopes marked blue is expected to interfere with the targeted species either due to low fission yields, half-lives or nonvolatility. Data were taken from Nucleonica [29]. 
apparent spontaneous fission rate of the ${ }^{252} \mathrm{Cf}$-source yielding products entering the chamber could be calculated. This activity could then be used as a reference value to estimate absolute yields for the measured MCC-species. This approach relies on the quality of the literature values for $y$-branching ratios, fission yields and the efficiency calibrations of the gamma detector for the different geometries of the activities on the charcoal traps and in the catcher foils. While the apparent spontaneous fission activity of the ${ }^{252} \mathrm{Cf}$ source was calculated with decent precision, literature values for $y$-branching ratios and fission yields for ${ }^{104} \mathrm{Mo},{ }^{107} \mathrm{Tc},{ }^{110} \mathrm{Ru}$ and ${ }^{111} \mathrm{Rh}$ as provided by Nucleonica [29] are all associated with large uncertainties. After error propagation, this results in large uncertainties for the observed trends not caused by the quality of the measured data. For this reason, the given relative yields reflect the precision of the actual measurement and therefore allow a clear evaluation of the observed trends.

However, in order to give an estimation of the order of magnitude chemical yields encountered during this study and to give a rough comparison of the absolute yields obtained for each investigated chemical species, Table 2 estimates the highest and lowest absolute chemical yields obtained for each species during the study presented here. The yields were calculated using the method mentioned above, based on catcher-foils. A detailed explanation is given in [31]. Again, it must be empathized that the high uncertainties associated with absolute yields do not reflect the precision of the measurements presented here, but are caused by the reference values required for calculation. Also it should be noted that it was possible to exceed the yields shown here in later studies using improved reaction conditions [31], indicating that the chemical yields shown here probably overestimate the true yields.

\subsection{Addition of gas-additives}

In this experiment series, the effects of various gas-additives $\left(\mathrm{O}_{2}, \mathrm{H}_{2} \mathrm{O}\right.$, $\mathrm{H}_{2}, \mathrm{CO}_{2}, \mathrm{CH}_{4}$ and air) on the formation and transport of MCCs were investigated. The gas-additives were either selected due to expected chemical interactions with Mo, Tc, Ru and $\mathrm{Rh}$ atoms or due to their initial abundance as general impurities in the used gases. In detail, the gas-additives were selected due to the following reasons:

(1) $\mathbf{C O}_{2}$ and $\mathbf{C H}_{4}$ were mainly selected due to their abundance as impurities in $\mathrm{CO}$ gas. $\mathrm{CH}_{4}$ was selected since it is the hydrocarbon showing the least adsorption on charcoal. Therefore, its subsequent removal from the process gas by the charcoal trap used for detection is less significant in comparison to higher hydrocarbons (see also chapter 3.2).

(2) $\mathbf{O}_{\mathbf{2}}$ and $\mathbf{H}_{\mathbf{2}} \mathbf{O}$ are common impurities expected to negatively impact the formation of MCCs due to possible side reactions.

Table 2: Highest and lowest absolute chemical yields for each MCC-species investigated during this study.

\begin{tabular}{lrr}
\hline Chemical Species & $\begin{array}{r}\text { Lowest chemical } \\
\text { yield, \% }\end{array}$ & $\begin{array}{r}\text { Highest chemical } \\
\text { yield, \% }\end{array}$ \\
\hline${ }^{104} \mathrm{Mo}(\mathrm{CO})_{6}$ & $7 \pm 2$ & $87 \pm 22$ \\
${ }^{107} \mathrm{Tc}(\mathrm{CO})_{n}$ & $3 \pm 1$ & $29 \pm 7$ \\
${ }^{110} \mathrm{Ru}(\mathrm{CO})_{5}$ & $11 \pm 5$ & $44 \pm 21$ \\
${ }^{111} \mathrm{Rh}(\mathrm{CO})_{m}$ & $4 \pm 1$ & $19 \pm 3$ \\
\hline
\end{tabular}

(3) $\mathbf{H}_{2}$ and Ar, $\mathrm{H}_{2}$ was expected to possibly cause the formation of volatile hydrides while Ar was shown in $[32,33]$ to form complexes of the type $\mathrm{M}(\mathrm{CO})_{n} \mathrm{Ar}$. Both effects were expected to potentially increase the amount of volatile reaction products.

(4) Air is an omnipresent source of impurities by diffusion-processes through polymer-tubing and/or small leaks.

The effect of $\mathrm{O}_{2}$ was previously investigated for Mo, Tc, $\mathrm{Ru}$ and $\mathrm{Rh}$ carbonyl complexes $[13,14,17]$ while the influence of $\mathrm{CO}_{2}$ was investigated for Mo [13]. It was decided to cross-check those investigations as an additional test for FORA. According to our knowledge, the influence of $\mathrm{H}_{2} \mathrm{O}, \mathrm{H}_{2}$ and $\mathrm{CH}_{4}$ has not been investigated before. Ar was indirectly investigated before by comparing $\mathrm{CO}: \mathrm{Ar}$ with $\mathrm{CO}: \mathrm{N}_{2}$ gas mixtures for Mo carbonyl formation [13].

2.4.1 $\mathbf{O}_{2}, \mathbf{H}_{2}, \mathbf{C O}_{2}, \mathrm{CH}_{4}$, air: These gas-additives were added to $100 \%$ $\mathrm{CO}$ at 1 bar and $1000 \mathrm{~mL} / \mathrm{min}$ gas flow. The investigated gas-additive concentrations were varied as $0.01,0.1,1$ and 10 vol- $\%$. In this concentration range, the dilution of $\mathrm{CO}$ is not expected to be significant. Since $\mathrm{O}_{2}, \mathrm{H}_{2}, \mathrm{CO}_{2}, \mathrm{CH}_{4}$ and air are all gaseous at room temperature, they can be easily added using one MFC (MFC4 in Figure 1). The same MFC was also used to remove process gas from the system in a well defined manner in order to keep the gas-pressure constant.

The MFC4 used for gas-additive handling was installed behind the charcoal trap, separated from the active FORA-loop by a valve (see Figure 1). This spot was chosen for two reasons: 1) The pressure in FORA is lowest between the charcoal trap and the metal bellows pump. Therefore, ambient air can be added very easily without the need of a compressor. 2) Removing gas at this spot avoids any influence on the charcoal trap. It was found that a gas stream in counter flow direction can cause a penetration of charcoal into the initial quartz-wool plugs, thereby considerably changing the measurement geometry.

The admixing procedure was the same for all gas-additives and is described below: MFC4 in conjunction with a turbomolecular pump was used to remove some process gas from the system in order to keep the total gas volume in FORA as constant as possible. Second, enough gas-additive was added to reach the desired additive concentration. Third, additional CO was added to achieve gas amounts equal to the initial one, thus obtaining same pressure and gas flow conditions as well as the intended partial pressure of the gas-additive. It was also taken into account that larger quantities of gas-additives added to CO might change the physical properties of the process gas. Namely, the gas correction factor required for a correct quantification of gas flows by MFCs might change. Therefore, the gas correction factor was adapted accordingly before each measurement according to [34]. All measurements had a duration of $3 \mathrm{~h}$. Process gas and charcoal trap were exchanged between each measurement. The turbomolecular pump (Hi-Cube ${ }^{\mathrm{TM}}$ ) from Pfeiffer $\mathrm{GmbH}$ already used in the first step of adding gas-additives was also used to evacuate FORA between the measurements with different gas-additives. The steel-containment mounted around the reaction chamber was always evacuated together with the entire loop. The entire procedure ensured that an accidental intake of air during manipulation of the process gas could be safely avoided.

The purification columns used were adapted to the chemical character of the gas-additive in order to not interfere with the targeted gas-additive but still keep the process gas as clean as possible otherwise. For Ar, a Sicapent ${ }^{\mathrm{TM}}$ (purchased from Merck) and MicroTorr 602F 
column purchased from Pure Gas Products were used. For $\mathrm{O}_{2}, \mathrm{CO}_{2}, \mathrm{CH}_{4}$ and $\mathrm{H}_{2}$, only the Sicapent ${ }^{\mathrm{TM}}$ column was online. For Air and water no columns were used at all. Sicapent ${ }^{\mathrm{TM}}$ is used to selectively remove water from the used gas mixture without affecting other gaseous impurities. The MicroTorr $602 \mathrm{~F}$ on the other hand is a purification columns specifically designed to remove $\mathrm{O}_{2}, \mathrm{H}_{2} \mathrm{O}, \mathrm{CO}_{2}$, MCCs, Acids, Bases and various other impurities from $\mathrm{CO}$ gas to impurity levels $<1 \mathrm{ppbv}$, therefore providing high degrees of gas purity.

The experimental conditions were kept unchanged for at least $24 \mathrm{~h}$ after evacuating and re-filling FORA to equilibrate the conditions. Additionally, the measurements performed for a gas-additive level of 1 vol- $\%$ were repeated four times right after each other. No strong, systematic change of signal was detected.

2.4.2 $\mathrm{H}_{\mathbf{2}} \mathrm{O}$ : Since water is not a gas at room temperature, its addition is not straight-forward. A built humidifier was used to add controlled amounts of water. Referring to Figure 1, "Column 1" of the purification setup was replaced with the humidifier. It was based on an ice-surface being held at a specific temperature to control the dew point of the gas flowing above the ice. It was filled with Milli-Q-water provided by an ELGA Flex 02 system from Labtec Services. The water was frozen at $-40{ }^{\circ} \mathrm{C}$ before the humidifier was evacuated. After evacuation, the process gas flow was redirected to travel through the humidifier. The temperature of the ice was quickly increased to obtain a high dew point to begin with. Then, a Sicapent ${ }^{\mathrm{TM}}$ column ("Column 2" in Figure 1) was periodically inserted to slowly decrease the dew point in a step-wise manner. As an additional control measurement, water was added again at the end of the series to check the reproducibility of the obtained data. The dew point monitored by the hygrometer was used to indicate the amount of water in the process gas. Both, the humidifier and the Sicapent ${ }^{\mathrm{TM}}$ column could be bypassed. $100 \% \mathrm{CO}$ was used to start with at a gas flow rate of $1000 \mathrm{~mL} / \mathrm{min}$ and a pressure of 1 bar.

2.4.3 Are gas-additives affecting formation or transport yields?: From a practical and theoretical standpoint, it is interesting to investigate if $\mathrm{O}_{2}$ and $\mathrm{H}_{2} \mathrm{O}$ are only reacting with metallic Mo, Tc, $\mathrm{Ru}$ and $\mathrm{Rh}$ prior to the formation of MCCs or also with MCCs themselves, thereby breaking metal-CO bonds. Unfortunately, FORA is not suitable for such kinds of investigations as it is constructed to be a gas-loop. Therefore, an older setup called Miss Piggy [28] was used that is based on the same operation principle as FORA but is operated in a oncethrough gas flow mode instead of a loop. This makes it possible to selectively add gas-additives at certain points of the system without their homogeneous distribution along the entire setup. Thus, the gas- additives come selectively into contact either with metallic atoms and with MCCs, or with MCCs only.

A modified version of the Miss Piggy setup located at the University of Bern was used for the investigations. The setup is schematically depicted in Figure 3.

The system is based on adding various reactive gases through multiple MFCs at well controlled rates and in well known ratios. A rotary vane pump provided by Leybold located after the charcoal trap was used to drive the gas flowing through the system and establish a constant pressure at about 900 mbar.

During operation, the initial two MFCs (MFC1 and MFC2) were used for mixing $\mathrm{CO}$ with either $\mathrm{N}_{2}$ or $\mathrm{O}_{2} / \mathrm{H}_{2} \mathrm{O}$. The resulting gas mixture was entering the reaction chamber, in which a ${ }^{252} \mathrm{Cf}$-source was located. The fission products were recoiling out of the source and thermalized in the reaction chamber, which was flushed with the gas mixture previously introduced. Volatile MCCs were formed and transported out of the reaction chamber by the gas stream into a second chamber (mixing chamber in Figure 5) through a $3 \mathrm{~m}$ long tube with an inner diameter of $2 \mathrm{~mm}$. There, a third gas could be added using an additional MFC (MFC3 in Figure 5). The constant, onedirectional gas-stream established by the rotary vane pump at the end of the setup stopped the additional gas from entering the reaction chamber as well, making sure that it only came into contact with already formed MCCs entering the mixing chamber. If MCCs survived the conditions of the mixing chamber, they were transported further by the process gas along another tube $(2 \mathrm{~m}$ length, $2 \mathrm{~mm}$ inner diameter) to a charcoal trap. There, the carbonyl complexes adsorbed on the charcoal and their decay was registered by $y$-spectroscopy. Spectra recording and evaluation were performed similarly as described for the FORA-setup.

Two separate series of experiments were performed, one using $\mathrm{O}_{2}$ and one using $\mathrm{H}_{2} \mathrm{O}$ as gas-additive. $\mathrm{O}_{2}$ was added using a MFC. For $\mathrm{H}_{2} \mathrm{O}$, a humidifier was used to moisten $\mathrm{N}_{2}$ prior to entering the setup. In this case, the dew point of the moistened $\mathrm{N}_{2}$ was monitored using a hygrometer. The dew point of the moistened gas was between 10 and $12{ }^{\circ} \mathrm{C}$. The built humidifier consisted of guiding $\mathrm{N}_{2}$ through a tube made from a $\mathrm{H}_{2} \mathrm{O}$ permeable membrane surrounded by water. Without adding water, the dew point of the process gas was between -10 and $-13^{\circ} \mathrm{C}$.

Gas-additives were alternatingly added from MFC2 before the reaction chamber or from MFC3 directly into the mixing chamber. To maintain stable flow and pressure conditions pure $\mathrm{N}_{2}$ was added from the MFCs not occupied by either adding $\mathrm{CO}$ or an gas-additive carrying gas. In between each measurement, a reference measurement using only $\mathrm{CO}$ and $\mathrm{N}_{2}$ was performed to ensure signal consistency. In summary, this resulted in the following three measurement conditions:

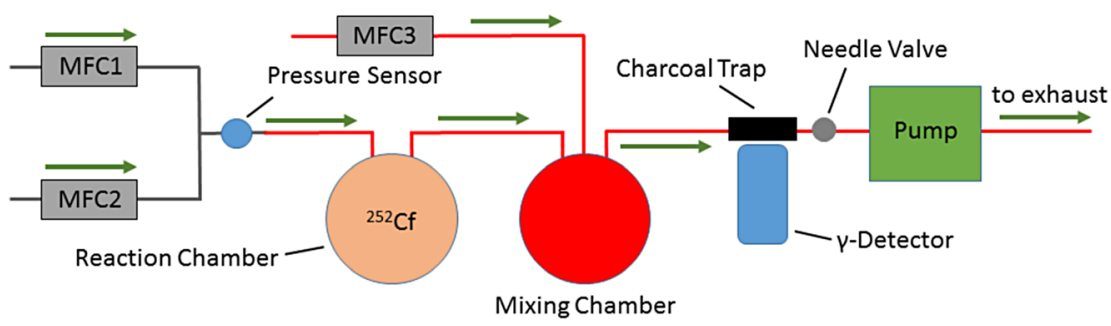

Mixing Chamber
Figure 5: Schematic of the modified Miss Piggy setup as used for the investigations. The gray lines indicate steel-tubes, the red ones PFA-TEFLON ${ }^{\circledR}$ tubes. The reaction and mixing chamber were both made of PFA-TEFLON ${ }^{\circledR}$. MFCs were used for adding and mixing gases. Note that MFC1 and MFC2 are adding gases into the reaction chamber while MFC3 adds gas into the mixing chamber. The setup is described in more detail in the text. The arrows indicate the gas flow. 
- No gas-additives added: MFC1: CO (600 smL/min); MFC2: $\mathrm{N}_{2}$ (100 smL/min); MFC3: $\mathrm{N}_{2}(100 \mathrm{smL} / \mathrm{min})$

- Gas-additives added into mixing chamber: MFC1: CO (600 smL/min); MFC2: $\mathrm{N}_{2}(100 \mathrm{smL} / \mathrm{min}) ; \mathrm{MFC} 3: \mathrm{O}_{2} / \mathrm{H}_{2} \mathrm{O}$ (100 smL/min)

- Gas-additives added into reaction chamber: MFC1: CO (600 smL/min); MFC2: $\mathrm{O}_{2} / \mathrm{H}_{2} \mathrm{O}(100 \mathrm{smL} / \mathrm{min}) ; \mathrm{MFC} 3: \mathrm{N}_{2}$ $(100 \mathrm{smL} / \mathrm{min})$

The reaction chamber and all surfaces in contact with the MCCs between the chamber and the charcoal trap were made from PFA-TEFLON ${ }^{\circledR}$. Connections were made using Swagelok ${ }^{\circledR}$ and BOLA ${ }^{\circledR}$ building parts. The mixing chamber had a cylindrical geometry with a volume of about $500 \mathrm{~mL}$ (height: $130 \mathrm{~mm}$, diameter: $70 \mathrm{~mm}$ ). The used charcoal trap was heated out at about $150^{\circ} \mathrm{C}$ with a small $\mathrm{N}_{2}$ gas flow applied to it (100 smL/min) prior to usage. For detection, a Canberra (Model: GR2519) HPGe-detector was used. The hygrometer (Easidew Transmitter, EA2-TX-100-HD) was provided by Michell Instruments and the pressure sensor (MAN-SD3S-A) was provided by Kobold. The MFCs (8580S) were purchased from Brooks. CO (99.997\%), $\mathrm{N}_{2}$ $(99.999 \%)$ and $\mathrm{O}_{2}(99.999 \%)$ were provided by Carbagas. The Miss Piggy setup was operated with $100 \mathrm{smL} / \mathrm{min}$ of $\mathrm{N}_{2}$ for $12 \mathrm{~h}$ prior to starting the two measurement series.

Each measurement had a duration of $30 \mathrm{~min}$. In analogy to the FORA-setup, Mo, Tc, and Ru MCCs were investigated at the same time. Unfortunately, $\mathrm{Rh}$ could not be reliably identified using this setup. Note that for measurements using Miss Piggy, standard gas flows are given ( $\mathrm{smL} / \mathrm{min}$ ) while for FORA measurements, the standard gas flow is always converted to the actual gas flow $(\mathrm{mL} / \mathrm{min})$. The reason for this is that despite Miss Piggy allowing to perform measurements at constant and reproducible pressure values, the pressure inside the reaction chamber is actually unknown. In FORA on the other hand, the pressure sensor is placed much closer to the reaction chamber. Additionally, the pressure in FORA was mapped at various positions in preparatory experiments during which it was determined that the pressure between the chamber and the charcoal trap (compare with figure LABEL:FORASetup) is almost constant during operation. Therefore, it is feasible to give actual gas flows in the case of FORA.

\section{Results and discussion}

\subsection{FORA-characterization}

A number of tests was performed to ensure the functionality of the newly constructed FORA-setup. The performance of the standardized charcoal traps was initially tested. For this, the FORA setup shown in Figure 1 was modified. A second charcoal trap was installed right after the first one and the activity adsorbed on this second trap (in flow direction) during operation was measured. No activity was measured on the second trap showing that the first one was sufficient to trap all radioactive MCCs arriving. Additionally, it was shown that all activity deposited on the first centimeters of the used charcoal trap even after one week of operation under well optimized reaction conditions. A continuous change of detection geometry due to changing adsorption characteristics of the charcoal trap can therefore be excluded. The second trap was removed again for the subsequent measurements.

Four measurements performed under identical reaction conditions within six months using the same process gas of $100 \%$ CO at 1 bar at a gas flow of $1000 \mathrm{~mL} / \mathrm{min}$, a Sicapent ${ }^{\mathrm{TM}}$ column for purification and different charcoal traps were compared for quantifying the reproducibility. The results were corrected for the decay of ${ }^{252} \mathrm{Cf}$. Thus, the quantitative reproducibility of the measurements using FORA was determined as $3 \%$ for ${ }^{104} \mathrm{Mo}$ and ${ }^{110} \mathrm{Ru}, 6 \%$ for ${ }^{107} \mathrm{Tc}$ and $7 \%$ for ${ }^{111} \mathrm{Rh}$. The calculation method is described in the supporting information.

The stability of the FORA-system is defined as the stability of the counting rate for a specific peak in the gamma-spectrum for a defined isotope (see chapter 2.2), corresponding to one of the investigated carbonyl species. Therefore, a stable system corresponds to a constant production yield for the investigated carbonyl species under constant reaction conditions in the FORA-system. The stability was investigated for a process gas of $100 \%$ CO at 1.00 bar and a gas flow of $1000 \mathrm{~mL} / \mathrm{min}$. For purification, only a Sicapent ${ }^{\mathrm{TM}}$ column was introduced to the loop in the gas purification setup (see Figure 1). After evacuating and filling FORA with fresh gas, continuously 1-h measurements were performed to monitor the performance of FORA as a function of time. The results are depicted in Figure 6. Despite constant pressure, dew point and gas flow over the course of the entire experiment, the obtained signal as a function of time increases quite drastically during the first few hours. After an initial waiting time of about $12 \mathrm{~h}$, the signal appears to be more stable. However, e.g. for ${ }^{104} \mathrm{Mo}$, the signal still increases by about $9.2 \%$ within the following $48 \mathrm{~h}$ (compare with Figure 6). The effect was intensively investigated and could be related to moisture and to the formation of stable carbonyl complexes from steel components of the loop in contact with CO [31]. To minimize interference by this behavior, all measurements using FORA were started after an initial waiting time of at least $12 \mathrm{~h}$ each time the CO-gas was exchanged. Subsequent measurements were always performed as fast as possible without reducing the quality of the obtained data. Additionally, the data shown in Figure 6 together with other long-term measurements using different setups of purification columns (see Supplementary Material) were used to estimate the effect of the time dependent change onto the data measured. Therefore, possible interferences are included in the error bars depicted in each plot. The exact procedure is described in detail in the supporting 

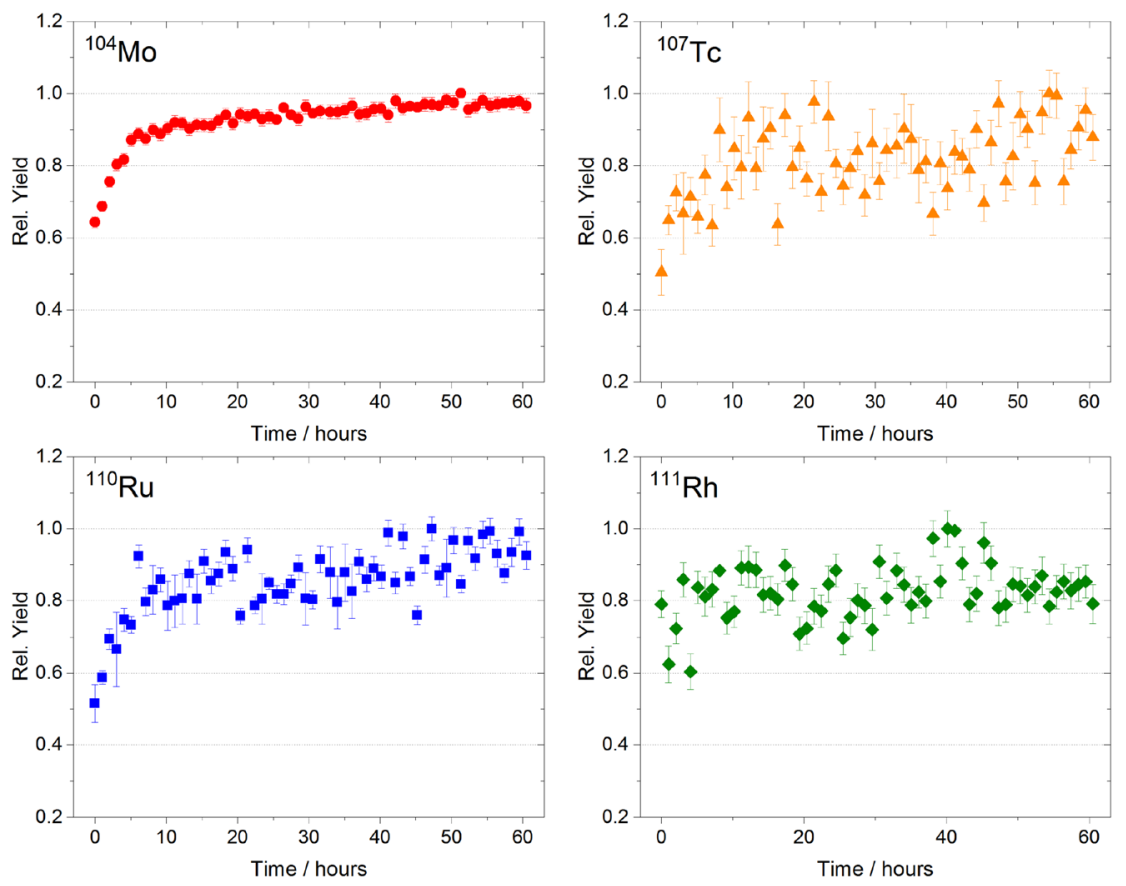

Figure 6: Signal-stability of FORA during long-term operation (details see text). The error bars correspond to the statistical error of the measurement. Continuously, $1 \mathrm{~h}$ measurements were performed. The data are normalized to the highest yield obtained for each element.

information. Error propagation was used to calculate uncertainties for all measurements with FORA that were not performed continuously. If not mentioned otherwise, the error bars therefore correspond to the propagation of the 2-sigma statistical counting error and systematic errors of each measurement series.

Generally lower counting statistics lead to larger error bars obtained for Tc, Ru and Rh in comparison with Mo. It is important to point out clearly that Mo, Tc, Ru and Rh are always investigated simultaneously. This means that the larger uncertainties in comparison with Mo are not due to systematic experimental fluctuations, but from higher sensitivities of Tc, Ru and Rh towards certain reaction parameters, poorer counting statistics due to lower amounts produced in ${ }^{252} \mathrm{Cf}$ fission and differing decay and detection characteristics.

\subsection{Potential experimental flaws or interferences}

Consecutively increasing the gas-additive concentration in the FORA process gas could potentially alter the stopping power of the process gas, which influences the range of fission products recoiling into the volume of the reaction chamber (Figure 2), influencing the observed yield independently from chemical effects. However, below 1 vol-\% of gas-additives, it is not expected that the stopping power of the process gas is significantly altered. Nevertheless, a series of simulations using the SRIM 2013.00 software by Ziegler et al. [35] was performed. The results can be found in the supporting information. In conclusion, for all gasadditives used in here, the alteration of fission product ranges can be neglected until 10 vol- $\%$. For 10 vol- $\%$ the ion stopping properties of the used process gas indeed start to vary slightly. In terms of ion ranges, for $\mathrm{CH}_{4}$, Ar and $\mathrm{O}_{2}$, the reduction of recoil range until thermalization is $<5 \%$. For $\mathrm{CO}_{2}$ and $\mathrm{H}_{2}$ the effect is $<10 \%$ decreasing for $\mathrm{CO}_{2}$ and increasing for $\mathrm{H}_{2}$.

An additional possible source of interference for the presented measurements is the slow, unintended accumulation of air and/or water either by diffusion through the polymer tubing of FORA or through small leaks. The effects of both air and water were investigated during this study. Both gas-additives were shown to negatively impact the formation and transport of MCCs with the exception of Tc. If the accidental intake and accumulation of air and water into the FORA-setup is assumed to be significant, one would expect a decrease in yield as a function of time. However, the longterm stability measurement shown in Figure 6 revealed a stable signal within the statistical uncertainty for all elements after an initial waiting period. Additionally, a Sicapent ${ }^{\mathrm{TM}}$ column was constantly used in all cases except for $\mathrm{H}_{2} \mathrm{O}$ and air, keeping the constantly monitored dew point in the process gas permanently at $<-100{ }^{\circ} \mathrm{C}$. Generally, neither dew point nor pressure did change during the investigations. Small amounts of air intake cannot be completely prevented. However, investigations with air (see section 3.5) show that 
the effect of ambient air on MCC-formation is only significant at air concentrations higher than $1 \mathrm{vol}-\%$.

Since the measurement series investigating the impact of $\mathrm{H}_{2} \mathrm{O}$ required more time to execute than the other gasadditive measurements, some data-points were measured twice on different days. Indeed, measurement points measured later showed a slightly lower yield in comparison with the previously measured ones. However, the difference was relatively small (about $10 \%$ for ${ }^{104} \mathrm{Mo}$ ). This might be due to the coverage of all PFA-Teflon ${ }^{\circledR}$ surfaces with water influencing the transport yield upon multiple adsorptions of the MCC together with water - an effect so far not investigated.

At last, it must be considered that the charcoal used for adsorbing and measuring radioactive MCCs is also adsorbing added gas-additives up to a certain degree. This is probably the most problematic source of interference since the amount of free gas-additive in FORA will always be lower than the actually added amount. The effect of charcoal trap adsorption on the remaining amount of gasadditives in the gas-phase was estimated by assuming a worst case scenario. Lopes et al. and Bazan et al. measured the adsorption equilibria of various gases on charcoal at 1 bar and $30{ }^{\circ} \mathrm{C}[36,37]$. These can be used to estimate the amount of adsorbed $\mathrm{CO}_{2}, \mathrm{CH}_{4}, \mathrm{H}_{2}$, Ar and $\mathrm{O}_{2}$ on a charcoal trap as used here. For simplicity, estimations are done for $100 \%$ gas-additive over charcoal with a given mass of $200 \mathrm{mg}$ at 1 bar and $30^{\circ} \mathrm{C}$. An equilibrium between adsorbed and gaseous additive is assumed. The results are shown in Table 3.

Table 3: Adsorption equilibria of a FORA charcoal trap (200 mg of coal) for the various gas-additives added (left). Calculations were done for a worst case scenario assuming $100 \%$ of the investigated gases in equilibrium with charcoal at 1 bar and at $30^{\circ} \mathrm{C}$. Data from $[36,37]$ were used for calculations. The Langmuir Isotherm described in [38] was use to extrapolate the data from Bazan et al. Details are given in the supporting information. For direct comparison, the volumes of gas-additives added to reach a certain gasadditive concentration in the FORA-setup are also shown (right).

\begin{tabular}{lr}
\hline Gas & Adsorbed amount [mL/trap] \\
\hline $\mathrm{CO}_{2}$ & 10.4 \\
$\mathrm{CH}_{4}$ & 4.6 \\
$\mathrm{O}_{2}$ & 1.2 \\
$\mathrm{Ar}$ & 1.2 \\
$\mathrm{H}_{2}$ & 0.15 \\
Concentration [vol-\%] & Volume [mL] \\
0.01 & 1 \\
0.1 & 10 \\
1 & 100 \\
10 & 1000 \\
\hline
\end{tabular}

In order to operate FORA at 1 bar and a gas flow of $1000 \mathrm{~mL} / \mathrm{min}$ an entire volume of about $10 \mathrm{~L}$ of gas is required to be in the system. Using this value and the ones in Table 3, the impact of charcoal trap adsorption onto free gas-additive concentration at various vol- $\%$ can be conservatively estimated. For $\mathrm{H}_{2}$, an effect is only expected for concentrations up to 0.01 vol- $\%$ while for $\mathrm{O}_{2}$, Ar, and $\mathrm{CH}_{4}$, a reduction of free concentration is possible up to 0.1 vol- $\%$. A more severe effect is expected for $\mathrm{CO}_{2}$, up to 1 vol- $\%$ in this simplified but conservative estimation. In practice, the trapping of gas-additives on charcoal is expected to be less significant due to the low partial pressures of the gas-additives, which is neglected here. The adsorption on charcoal will be most severe for $\mathrm{H}_{2} \mathrm{O}$. However, since the dew point of the process gas when entering the reaction chamber is continuously measured, this is not of concern for this study.

The adsorption profile of radioactive carbonyls on the various charcoal traps has been checked at multiple occasions during the operation of FORA. Radioactive species were always deposited on the first $\mathrm{cm}$ of the trap, independent of the operation conditions.

\subsection{FORA: $\mathrm{O}_{2}, \mathrm{H}_{2}, \mathrm{CO}_{2}, \mathrm{CH}_{4}$}

The results for the investigated gas-additives are shown in Figures 7-11. Contrary to $\mathrm{CO}_{2}, \mathrm{H}_{2}, \mathrm{CH}_{4}$ and $\mathrm{Ar}, \mathrm{O}_{2}$ and air are both causing a reduction of the observed MCC-yield for all investigated elements.

While the formation of MCCs for Mo and Ru is clearly not impacted by $\mathrm{CO}_{2}, \mathrm{CH}_{4}, \mathrm{H}_{2}$ and Ar gas-additives even at higher concentrations, lower measurement statistics for Tc and $\mathrm{Rh}$ make an interpretation of the obtained data more difficult. However, for Tc, the addition of $\mathrm{CO}_{2}, \mathrm{CH}_{4}, \mathrm{H}_{2}$ and $\mathrm{Ar}$, and for $\mathrm{Rh}$, the addition of $\mathrm{CH}_{4}, \mathrm{H}_{2}$ and $\mathrm{Ar}$ are not significantly affecting the yield. The influence of $\mathrm{CO}_{2}$ concentrations $\geq 10$ vol- $\%$ on the yield of $\mathrm{Rh}$ remains unexplained, though.

It was assumed that $\mathrm{H}_{2}$ addition to the process gas might increases the yield for Tc and Rh due to the formation of carbonyl-hydride compounds (e.g. $\mathrm{TcH}(\mathrm{CO})_{5}$ or $\left.\mathrm{RhH}(\mathrm{CO})_{4}[30,39]\right)$. This is not confirmed by our results. For Ar, it was assumed that the formation of nobel-gas-adducts (e.g. $\mathrm{Mo}(\mathrm{CO})_{5} \mathrm{Ar}$ ) might positively impact the obtained yield $[32,33]$. This is also not confirmed by our data. The nonsensitivity towards $\mathrm{CH}_{4}$ implies that an impact of volatile hydrocarbons, being a common impurity in $\mathrm{CO}$, should not be of concern either. The same was found for $\mathrm{CO}_{2}$. The data obtained with $\mathrm{CO}_{2}, \mathrm{CH}_{4}, \mathrm{H}_{2}$ and Ar as gas-additives indicate that the approach used here is well justified. If dilution 

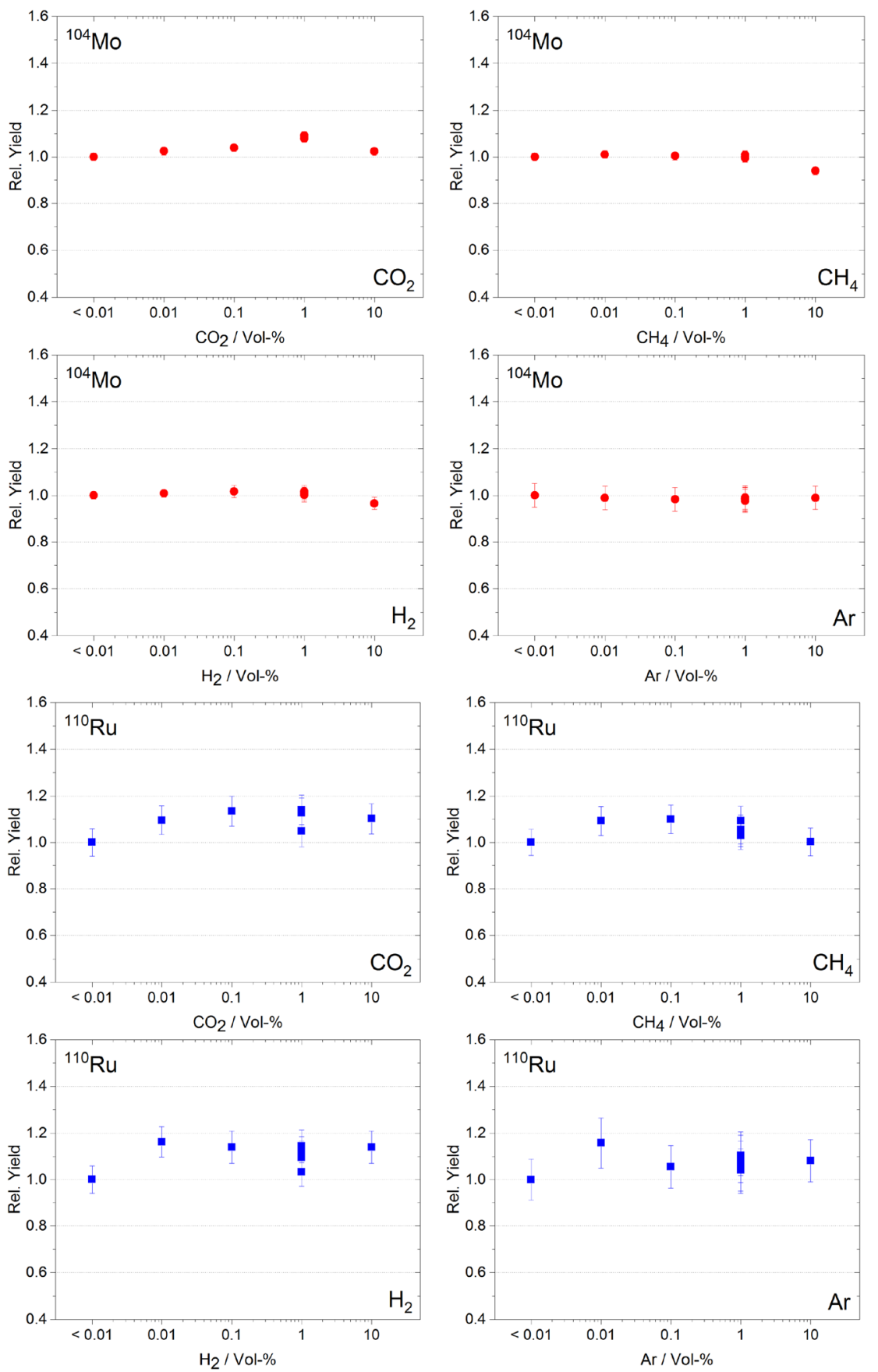

Figure 7: Relative yields obtained for ${ }^{104} \mathrm{Mo}$ (four top panels) and ${ }^{110} \mathrm{Ru}$ (four bottom panels) for adding varied amounts of $\mathrm{CO}_{2}$, $\mathrm{CH}_{4}, \mathrm{H}_{2}$ and $\mathrm{Ar}$ to $100 \% \mathrm{CO}$. The first measurement point (at $>0.01 \mathrm{vol}-\%$ ), corresponds to the first spectrum measured without any gas-additives added and is used for normalization.

effects of $\mathrm{CO}$ upon addition of gas-additives or a change in stopping power properties significantly affected the obtained MCC-yield, it would be rather unlikely to observe the same constant signals for all investigated systems here.

Our data are confirming previous studies by Usoltsev et al. [13] concerning the influence of $\mathrm{O}_{2}$ onto MCC formation for Mo. $\mathrm{O}_{2}$ is reducing the chemical formation yield for $\mathrm{Mo}(\mathrm{CO})_{6}$. For Tc, the influence of $\mathrm{O}_{2}$ onto the formation yield resembles the one for Mo. On the other hand, $\mathrm{Ru}$ is less affected by high $\mathrm{O}_{2}$ levels than Mo and Tc. Rh shows an almost linear dependency towards $\mathrm{O}_{2}$ concentration levels. This indicates $\mathrm{Rh}$ being sensitive towards $\mathrm{O}_{2}$ even at lower concentrations. The trend is considered to be significant due to the low scattering of the measured values and the continuous trending.

While the conclusions for Tc are in agreement with previous work by Wang et al. [17], the observations for Ru and $\mathrm{Rh}$ are not agreeing with results from [14], where $\mathrm{O}_{2}$ did not impact the formation of MCCs from Ru and Rh. However, within the statistical error the two data sets are in 

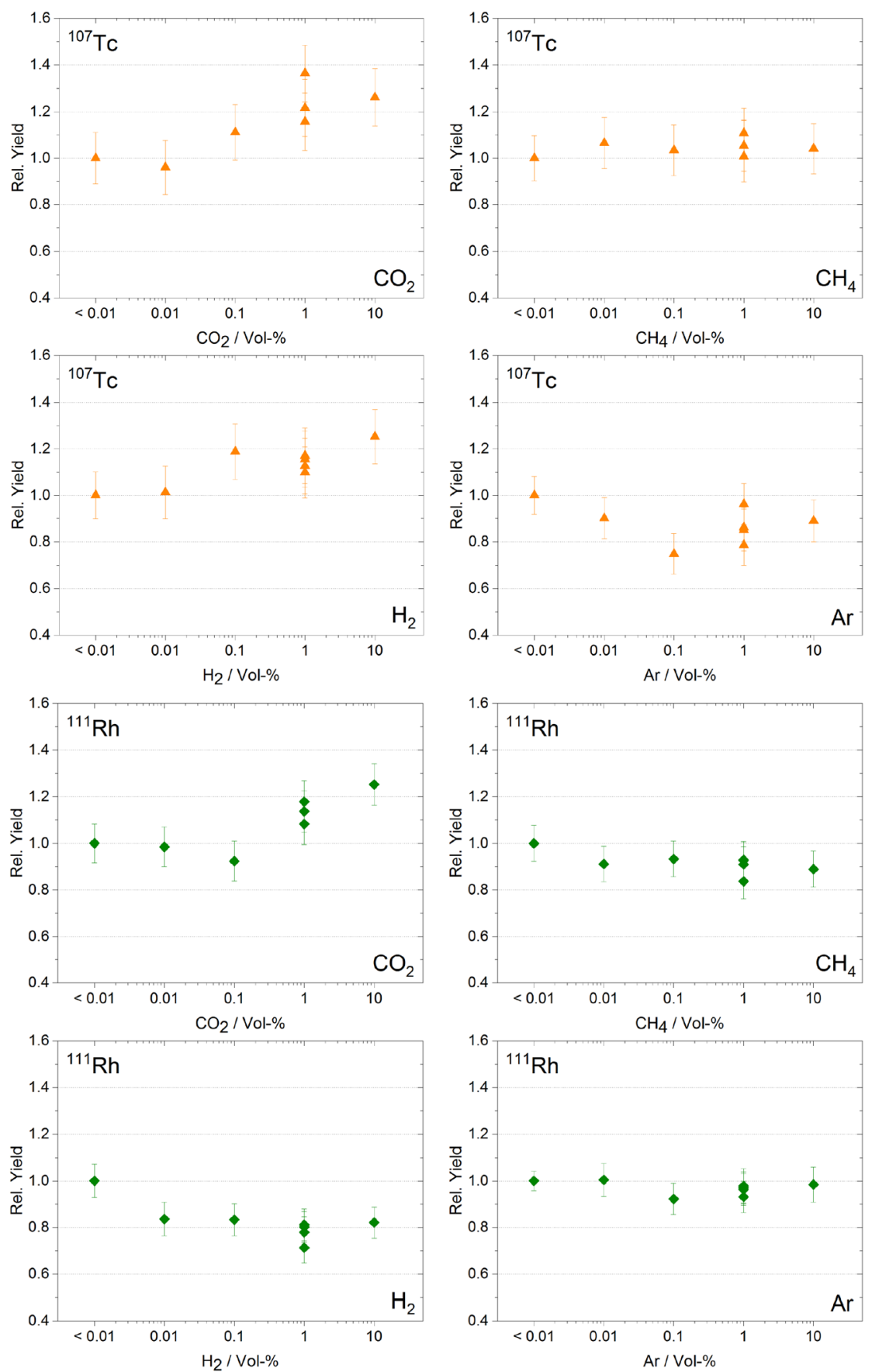

Figure 8: Relative yields obtained for ${ }^{107} \mathrm{Tc}$ (four top panels) and ${ }^{111} \mathrm{Rh}$ (four bottom panels) for adding varied amounts of $\mathrm{CO}_{2}$, $\mathrm{CH}_{4}, \mathrm{H}_{2}$ and $\mathrm{Ar}$ to $100 \% \mathrm{CO}$. The first measurement point (at $>0.01$ vol- $\%$ ), corresponds to the first spectrum measured without any gas-additives added and is used for normalization. decent agreement. The effect of $\mathrm{O}_{2}$ onto MCC formation yields for $\mathrm{Ru}$ and $\mathrm{Rh}$ is concluded to be significant, but small in comparison with the effect on the formation yields of MCCs for Mo and Tc.

The reduction of MCC yield upon $\mathrm{O}_{2}$ addition can be attributed to the synthesis of non-volatile side products. Under the reducing conditions of a CO-atmosphere, the formation of lower oxidation state oxides is expected. E.g., $\mathrm{RuO}_{4}$ is actually unlikely to form under these conditions, if formed it would have led to increased transport yields for
$\mathrm{Ru}$ upon addition of oxygen to the carrier gas, due to its volatility. However, the formation of stable dioxides, $\mathrm{MoO}_{2}$, $\mathrm{TcO}_{2}, \mathrm{RuO}_{2}$ and $\mathrm{RhO}_{2}$, which are all known to be not volatile for group 6-9 elements, can be expected [40]. In regard of recently published mass spectrometric studies by Wang et al. [15], a yield drop due to the formation of oxocarbonyl-complexes can not be excluded as well if they are not volatile.

It is important to point out that a rather large concentration of $\mathrm{O}_{2}$ is necessary to observe any impact. For Mo, a 

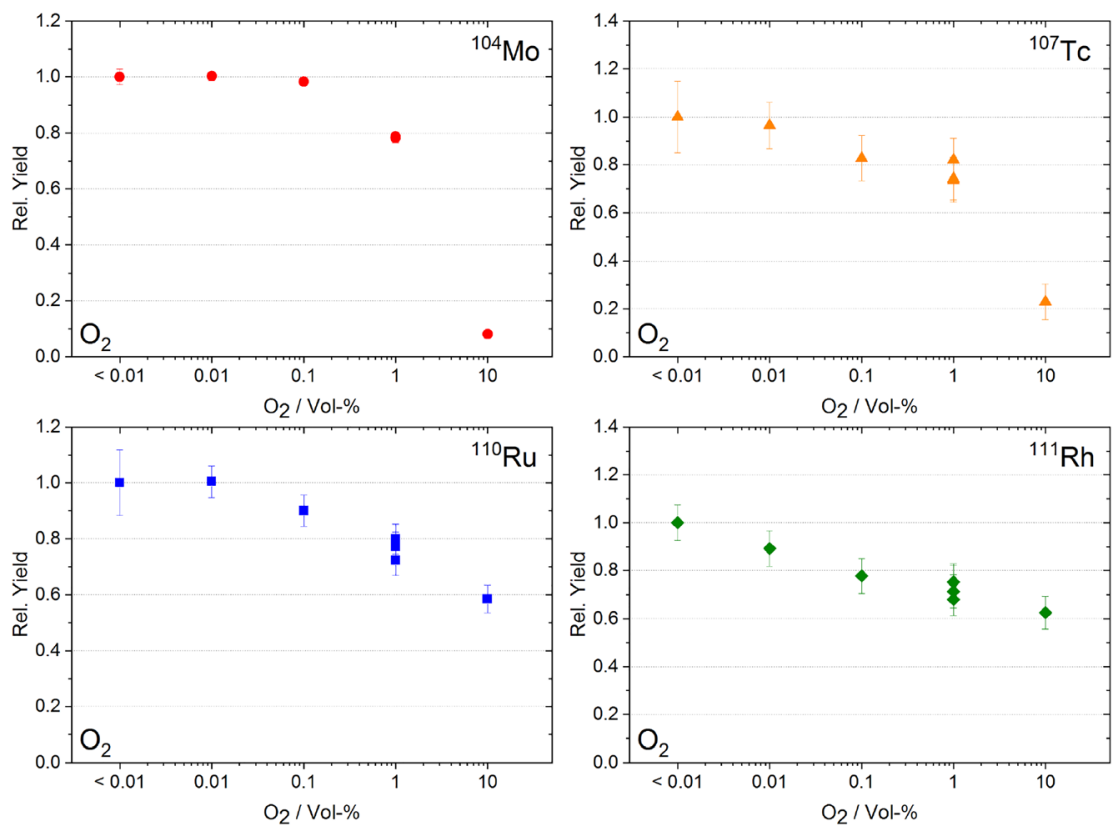

Figure 9: Relative yields obtained for all investigated isotopes for adding varied amounts of $\mathrm{O}_{2}$ to $100 \% \mathrm{CO}$. The first measurement point (at $>0.01 \mathrm{vol}-\%$ ), corresponds to the first spectrum measured without any gas-additives added and is used for normalization.

significant effect was only visible at $\mathrm{O}_{2}$ concentrations as high as 1 vol-\%. During previous, accelerator-based studies, the yield for the formation of $\mathrm{Mo}(\mathrm{CO})_{6}$ was determined to be only about $40 \%$ [26]. It was assumed, that this might be caused by $\mathrm{O}_{2}$-impurities being present in the process gas during those experiments. According to the presented data, this is actually very unlikely. Since $\mathrm{O}_{2}$ concentrations around 1 vol- $\%$ are necessary for $\mathrm{O}_{2}$ to affect Mo, a similarly high concentration of $\mathrm{O}_{2}$ would have been necessary in the accelerator-based measurements in order to affect the yield. This concentration level seems to be rather high to be reached accidentally. This therefore suggests that $\mathrm{O}_{2}$-impurities are not the cause for the low $\mathrm{Mo}(\mathrm{CO})_{6}$ yields observed in the accelerators-based experiments. Note however that the low yields for $\mathrm{W}(\mathrm{CO})_{6}$ and $\mathrm{Sg}(\mathrm{CO})_{6}$ could be at least partially caused by $\mathrm{O}_{2}$ since $\mathrm{W}$ and $\mathrm{Sg}$ are expected to be more reactive towards oxygen than Mo [13, 41].

\subsection{FORA: $\mathrm{H}_{2} \mathrm{O}$}

The combined data obtained for the two measurement series involving the addition of $\mathrm{H}_{2} \mathrm{O}$ are shown in Figure 10.

While $\mathrm{O}_{2}$ is indeed diminishing the formation of MCCs in general, it has to be present in rather high concentrations to show an effect. In this context, the situation for $\mathrm{H}_{2} \mathrm{O}$ is very different. For Mo, a significant yield reduction is already observed at a dew point of about $-80{ }^{\circ} \mathrm{C}$, corresponding to about 0.55 ppmv. Between -50 and $-40{ }^{\circ} \mathrm{C}$ (ca $40-$ 130 ppmv), a sudden drop in yield of about 30\% occurs. For
$\mathrm{Ru}$, reduction of yield also starts around $-80^{\circ} \mathrm{C}(0.55 \mathrm{ppmv})$. It is important to point out the low concentrations of $\mathrm{H}_{2} \mathrm{O}$ used in this study, especially in comparison with $\mathrm{O}_{2}$. While 1 vol- $\%$ of $\mathrm{O}_{2}$ were necessary to impact the chemical yield of presumably $\mathrm{Mo}(\mathrm{CO})_{6}$, a few ppmv of water were shown to already have a similar effect. The calculation of ppmv from dew point values was performed using the humidity calculator from Michell Instruments [42].

Surprisingly, Tc appears not to be significantly affected by $\mathrm{H}_{2} \mathrm{O}$ below dew points of $-40{ }^{\circ} \mathrm{C}$ (ca 130 ppmv). Above $-40{ }^{\circ} \mathrm{C}$, an increase in yield was observed. It was suggested by Pershina et al. that Tc is transported as volatile $\mathrm{TcH}(\mathrm{CO})_{5}$ due to reaction with $\mathrm{H}_{2} \mathrm{O}$-impurities in the process gas [30]. In this case, the increasing yield observed for Tc upon addition of $\mathrm{H}_{2} \mathrm{O}$ could be caused by a facilitated synthesis of $\mathrm{TcH}(\mathrm{CO})_{5}$ or potentially a volatile carbonylhydroxide species. The formation of the rather volatile $\mathrm{HTcO}_{4}$ can be disregarded at the reducing conditions of the CO-rich atmosphere. Therefore, synthesis of stable volatile low oxidation state oxo-hydroxides or pure hydroxides can be expected only. These were observed in mass spectrometric studies with Tc under slightly oxidizing conditions to be stable, but with an unknown volatility [43]. Unfortunately, the single atom studies presented here do not allow for product speciation by default.

The data obtained for Rh do not provide a clear picture. The obtained data-points are scattered by $\pm 40 \%$ around the first measurement point of the series, measured before addition of $\mathrm{H}_{2} \mathrm{O}$.

Figure 10 reveals that some data-points are systematically lower than others, particularly well visible for ${ }^{104} \mathrm{Mo}$ 

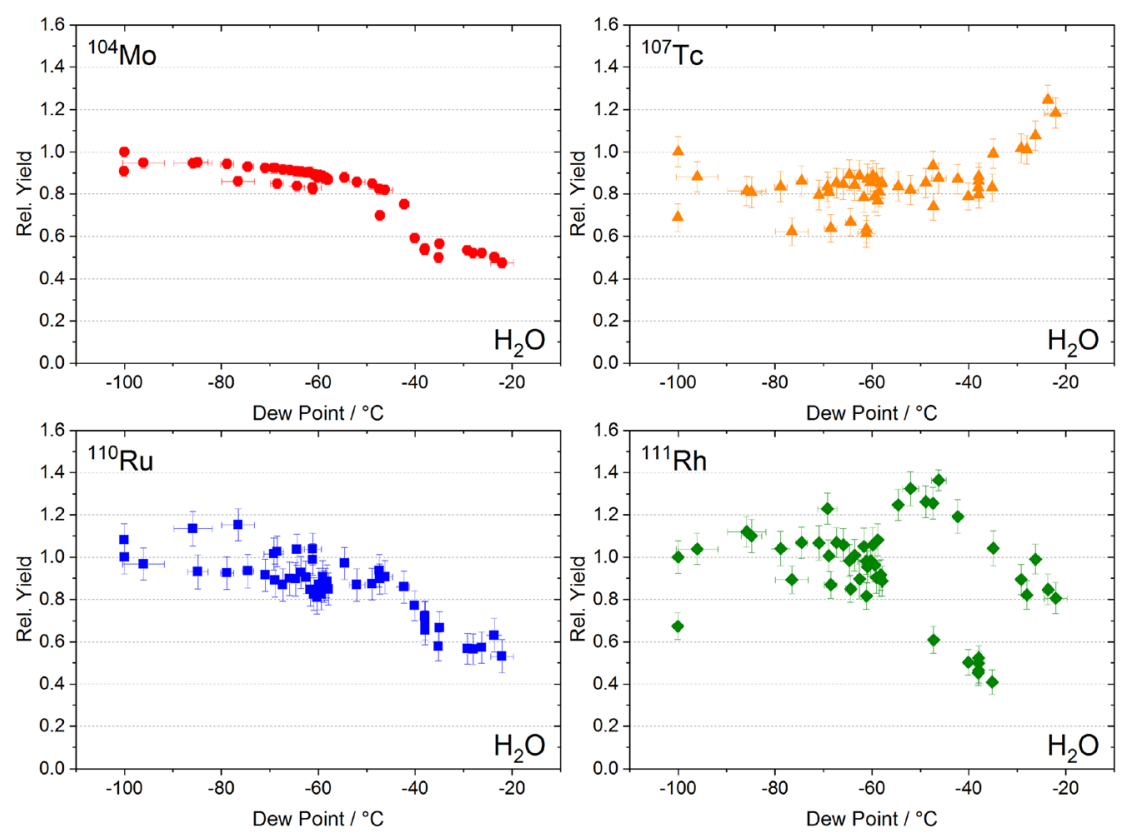

Figure 10: Relative yields obtained for adding varied amounts of $\mathrm{H}_{2} \mathrm{O}$ to the FORA-setup. The data are normalized to the very first measurement of the series, before any $\mathrm{H}_{2} \mathrm{O}$ was added (at $<0.01$ vol- $\%$ ).

between -80 and $-40{ }^{\circ} \mathrm{C}$. Those are actually the data points measured during the control measurements, where after drying the gas, water was added again (see Section 2.4.2). The "drying" of the gas does not lead to the same drying of the surfaces, because desorption of water from the surfaces is typically a slow process. Therefore larger concentrations of water in the gas phase can be expected during the control measurements, because there is no more any loss to the surfaces, which are still occupied by adsorbed water, compared to the initial first measurements.

The initial increase in yield observed in the FORA-system after exchanging the process gas (see Figure 6) can also be attributed at least partially to the removal of $\mathrm{H}_{2} \mathrm{O}$ from the gas phase and from the walls by drying due to the Sicapent ${ }^{\mathrm{TM}}$ column during loop operation. It cannot be excluded, that water adsorbed on the inner steel and PFA-TEFLON ${ }^{\circledR}$ surface of the entire FORA setup lowers the initially observed yield due to reactions of adsorbed MCCs with adsorbed water. Additional experiments are required to bolster this hypothesis. However, a heating of the entire loop setup during the drying operation is highly recommended. Generally, we expect the formation of non-volatile lower oxidation state hydroxides, oxohydroxides, hydroxocarbonyls or/and oxohydroxocarbonyls to be responsible for the observed decrease in yield for Mo, $\mathrm{Ru}$ and $\mathrm{Rh}$.

This work suggests humidity to be more problematic than $\mathrm{O}_{2}$-content. For $\mathrm{Mo}$ and $\mathrm{Ru}$, reduction of yield upon water addition was significant already at very low concentrations. Thus, keeping the process gas dry is of utmost importance for investigating Mo and Ru MCCs. For Tc on the other hand, the observed increase in yield might even provide an opportunity for group 7 investigations. However, further investigations concerning this observation and the speciation of the compounds formed at high dew points are necessary. For Rh, the obtained data are not conclusive due to strong scattering. This is surprising as it is not typical for $\mathrm{Rh}$ in the FORA-system to show such a strong scattering. This work indicates that $\mathrm{Rh}$ shows $\mathrm{a}$ complex behavior towards $\mathrm{H}_{2} \mathrm{O}$ traces, including effects on the formation as well as on the adsorption/decomposition during the transport of the MCC's.

\subsection{FORA: air}

The results obtained for adding air are shown in Figure 11. Like $\mathrm{O}_{2}$, air caused a reduction in yield upon its addition.

As expected in comparison with measurements for $\mathrm{O}_{2}$ and $\mathrm{H}_{2} \mathrm{O}$, also air is decreasing the formation and transport yields of MCCs. This can be attributed most likely to the $\mathrm{O}_{2}$ and $\mathrm{H}_{2} \mathrm{O}$ content in air. Indeed, since the amount of $\mathrm{O}_{2}$ in air can be estimated to be about $20 \%$ and the dew point in FORA was monitored during the entire study, it is possible to compare the results obtained for adding air with the ones shown previously for $\mathrm{O}_{2}$ and $\mathrm{H}_{2} \mathrm{O}$.

Assuming that indeed, the influence of air is only an effect of $\mathrm{O}_{2}$ and $\mathrm{H}_{2} \mathrm{O}$, it was attempted to predict the reaction of the carbonyl formation reaction towards various amounts of air added. The results are shown in Figure 12 and compared with the experimentally obtained data. The data obtained for $\mathrm{O}_{2}$ and $\mathrm{H}_{2} \mathrm{O}$ addition were fitted with 

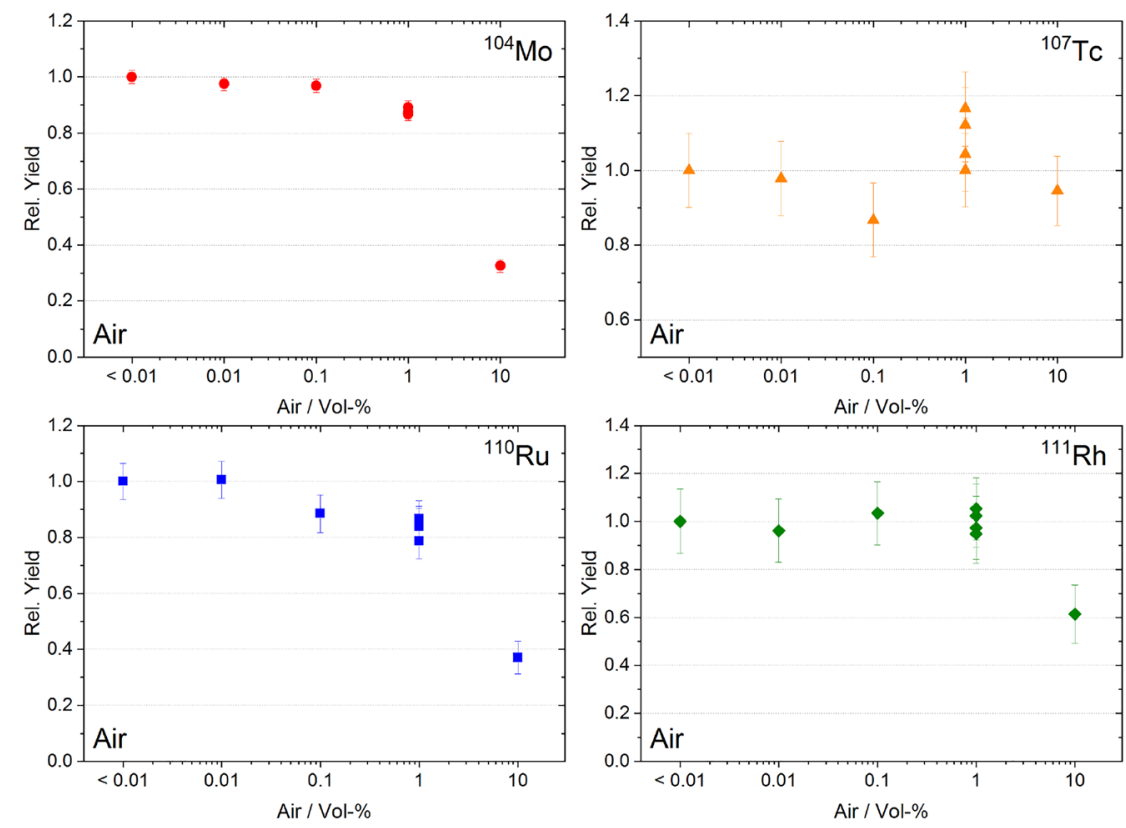

Figure 11: Relative yields obtained for all investigated isotopes for adding varied amounts of ambient air to $100 \% \mathrm{CO}$. The first measurement point (at $>0.01 \mathrm{vol}-\%$ ), corresponds to the first spectrum measured without any gas-additives added and is used for normalization.

suitable functions for this purpose to allow extrapolation to $\mathrm{O}_{2} / \mathrm{H}_{2} \mathrm{O}$-concentrations that were not experimentally investigated. The chosen fitting functions are considered empirical. A description of the fitting functions is given in the supporting information. The impact of $\mathrm{O}_{2}$ and $\mathrm{H}_{2} \mathrm{O}$ in air was assumed to be additive for the prediction.

For ${ }^{104} \mathrm{Mo}$, it is remarkable how well the predictions based on the individual behavior of $\mathrm{O}_{2}$ and $\mathrm{H}_{2} \mathrm{O}$ are matching the experimental data obtained for air. As can be seen in the upper left panel in Figure 12, the prediction is in excellent agreement with the measurement, indicating not only that indeed, the effects of air on MCC formation is probably primarily related to $\mathrm{O}_{2}$ and $\mathrm{H}_{2} \mathrm{O}$ in air, but also being in agreement with the conclusions made above for oxygen and water.

For ${ }^{110} \mathrm{Ru}$ prediction and measurement are in good agreement as well, again indicating that the effect of air is mainly caused by $\mathrm{O}_{2}$ and $\mathrm{H}_{2} \mathrm{O}$. The prediction overestimates the yield at 10 vol- $\%$ of air, but the overall trend appears to be well described. For ${ }^{107} \mathrm{Tc}$ and ${ }^{111} \mathrm{Rh}$, prediction and measurement do not agree. For ${ }^{107} \mathrm{Tc}$, agreement could be improved by assuming no impact of $\mathrm{H}_{2} \mathrm{O}$ until a dew point
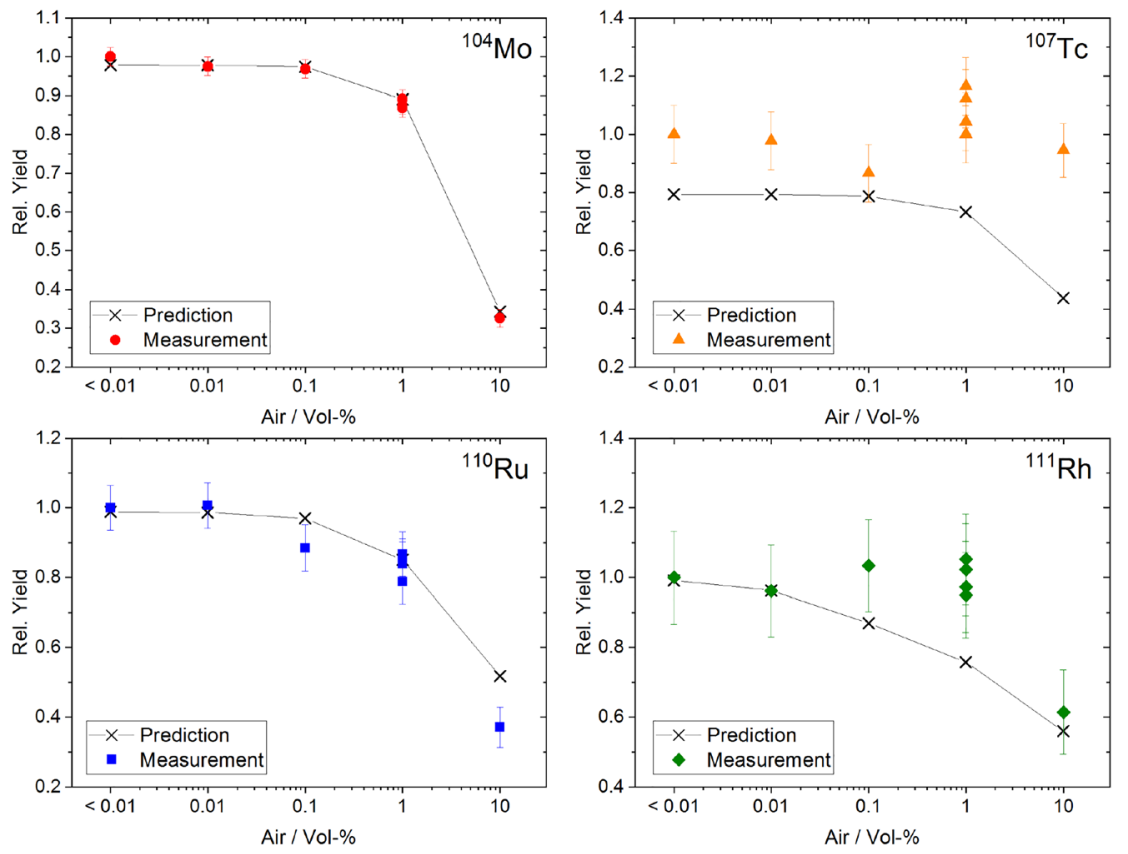

Figure 12: Comparison between the experimentally measured relative yields for addition of air and the expected ones, assuming that only $\mathrm{O}_{2}$ and $\mathrm{H}_{2} \mathrm{O}$ introduced with air are reducing formation and/or transport yields for MCCs. The colored symbols represent the experimental results for adding air as shown in Figure 11. The black crosses connected by lines represent the expected yields. The effects of $\mathrm{O}_{2}$ and $\mathrm{H}_{2} \mathrm{O}$ are assumed to be additive and are determined by fitting the data depicted in Figures 9 and 10 to empirical functions. Details are given in the supporting information. 
of $-50{ }^{\circ} \mathrm{C}$. However, even with this assumption, yields at 10 vol- $\%$ of added air are still predicted too low.

\subsection{Are gas-additives affecting formation or transport yields?}

The results obtained for $\mathrm{O}_{2}$ are depicted in Figure 13 . Particularly for ${ }^{104} \mathrm{Mo}$ (top panel in Figure 13) the effect of $\mathrm{O}_{2}$ is nicely visible. It appears that if $\mathrm{O}_{2}$ is added to the process gas after MCC formation is already complete (i.e. into the mixing chamber), the chemical yield only slightly decreases in comparison with reference measurements. On the other hand, adding $\mathrm{O}_{2}$ at the very beginning of the measurement system, so it enters the reaction chamber and comes into contact with ${ }^{252} \mathrm{Cf}$ fission products prior to MCC formation, does significantly reduce the yield measured at the charcoal trap to almost 0 for ${ }^{104} \mathrm{Mo}$.

For ${ }^{110} \mathrm{Tc}$, the picture is rather similar to ${ }^{104} \mathrm{Mo}$. However, the yield obtained for adding $\mathrm{O}_{2}$ into the mixing chamber appears to be lowered to a greater extent in comparison with ${ }^{104} \mathrm{Mo}$. The larger error bars for ${ }^{107} \mathrm{Tc}$ in comparison with

${ }^{104} \mathrm{Mo}$ and ${ }^{109} \mathrm{Ru}$ are caused by a combination of smaller

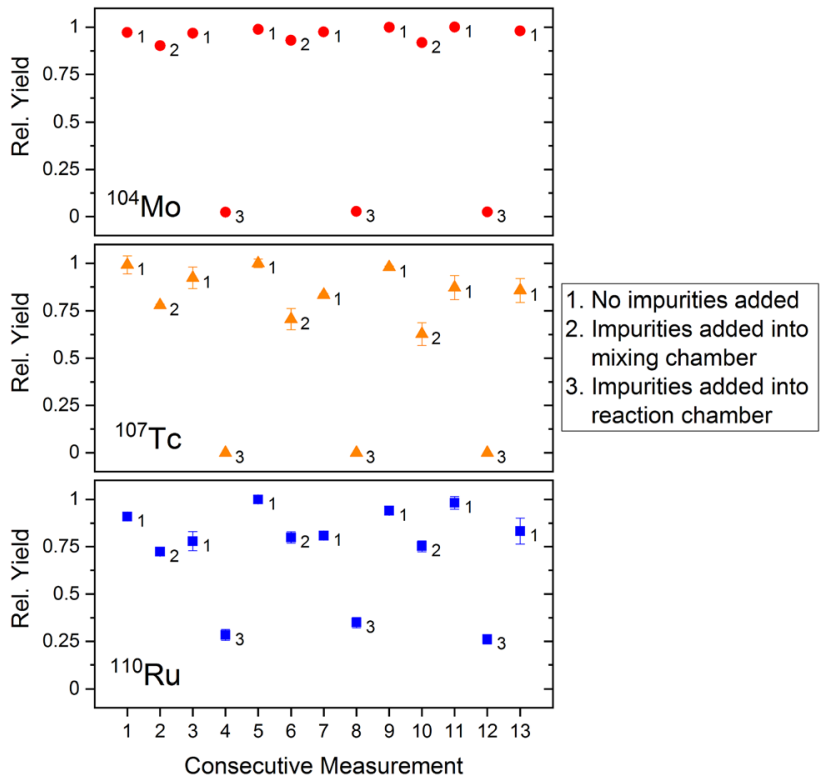

Figure 13: Relative yields obtained using $\mathrm{O}_{2}$ as gas-additive for the three isotopes investigated. The results were normalized to the maximum obtained yield. The error-bars correspond to the statistical error of the measurement. The small numbers next to each measurement point indicate the experimental conditions: (1) MFC1: CO $(600 \mathrm{smL} / \mathrm{min})$, MFC2: $\mathrm{N}_{2}(100 \mathrm{smL} / \mathrm{min})$, MFC3: $\mathrm{N}_{2}(100 \mathrm{smL} /$ $\mathrm{min})$; (2) MFC1: CO (600 smL/min), MFC2: $\mathrm{N}_{2}(100 \mathrm{smL} / \mathrm{min})$, MFC3: $\mathrm{O}_{2}(100 \mathrm{smL} / \mathrm{min}) ;(3) \mathrm{MFC} 1: \mathrm{CO}(600 \mathrm{smL} / \mathrm{min}), \mathrm{MFC} 2: \mathrm{O}_{2}(100 \mathrm{smL} /$ $\min )$, MFC3: $\mathrm{N}_{2}(100 \mathrm{smL} / \mathrm{min})$. yields, shorter half-life and a smaller $y$-branching ratio for the investigated ${ }^{107} \mathrm{Tc}$ peak.

For ${ }^{110} \mathrm{Ru}$ (bottom panel in Figure 13), measurements 9-11 imply a lowered yield upon adding $\mathrm{O}_{2}$ into the mixing chamber as well. However, this behavior was not well reproduced (measurements $1-3$ and $5-7$ ). The yield is again most strongly lowered if $\mathrm{O}_{2}$ is added into the reaction chamber.

The results obtained for $\mathrm{H}_{2} \mathrm{O}$ are depicted in Figure 14 . The effect of $\mathrm{H}_{2} \mathrm{O}$ is mostly pronounced for ${ }^{104} \mathrm{Mo}$. All three investigated elements are more sensitive towards $\mathrm{H}_{2} \mathrm{O}$ if it is added into the reaction chamber, coming into contact with ${ }^{252} \mathrm{Cf}$ fission products prior to MCC formation. In agreement with previous FORA-measurements, ${ }^{107} \mathrm{Tc}$ is only weakly affected by $\mathrm{H}_{2} \mathrm{O}$.

The data obtained using the mixing chamber and Miss Piggy suggest that mostly elemental Mo, Tc and $\mathrm{Ru}$ are sensitive towards $\mathrm{O}_{2}$ and $\mathrm{H}_{2} \mathrm{O}$, while the corresponding MCCs are much less reactive. For Mo, the effect was very clearly observed with ${ }^{104} \mathrm{Mo}(\mathrm{CO})_{6}$ being less sensitive towards $\mathrm{O}_{2}$ and $\mathrm{H}_{2} \mathrm{O}$ in contrast to metallic ${ }^{104} \mathrm{Mo}$. For Tc and $\mathrm{Ru}$, the data indicate a larger sensitivity of the corresponding MCCs towards $\mathrm{O}_{2}$ and $\mathrm{H}_{2} \mathrm{O}$ than for $\mathrm{Mo}(\mathrm{CO})_{6}$.

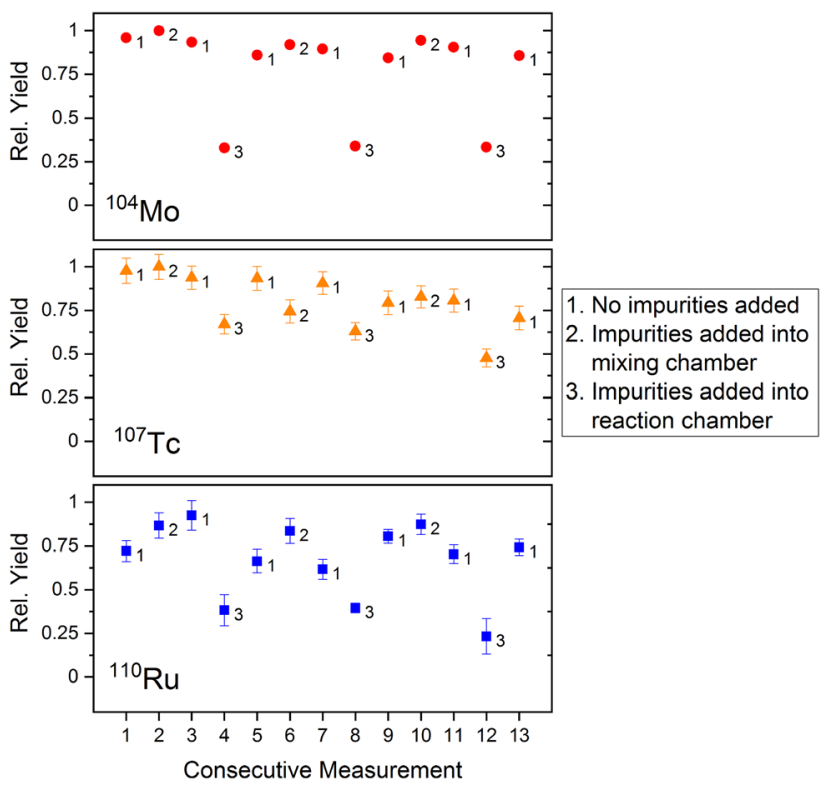

Figure 14: Relative yields obtained using $\mathrm{H}_{2} \mathrm{O}$ as gas-additive. The results were normalized to the maximum obtained yield. The errorbars correspond to the statistical error of the measurement. The small numbers next to each measurement point indicate the experimental conditions: (1) MFC1: $\mathrm{CO}(600 \mathrm{smL} / \mathrm{min}), \mathrm{MFC2}: \mathrm{N}_{2}$ (100 smL/min), MFC3: $\mathrm{N}_{2}(100 \mathrm{smL} / \mathrm{min})$; (2) MFC1: CO $(600 \mathrm{smL} /$ $\mathrm{min}), M F C 2: \mathrm{N}_{2}(100 \mathrm{smL} / \mathrm{min}), M F C 3: \mathrm{H}_{2} \mathrm{O}$ in $\mathrm{N}_{2}(100 \mathrm{smL} / \mathrm{min})$; (3) MFC1: CO (600 smL/min), MFC2: $\mathrm{H}_{2} \mathrm{O}$ in $\mathrm{N}_{2}(100 \mathrm{smL} / \mathrm{min})$, MFC3: $\mathrm{N}_{2}$ $(100 \mathrm{smL} / \mathrm{min})$. 
It is unfortunate that MCCs from Rh could not be observed at all. This is most likely related to the apparent higher sensitivity of Rh towards impurities and the fact that gases introduced into Miss Piggy are used once and without further purification. It is considered to be possible that the higher sensitivity of Rh towards trace amounts of impurities might be enhanced by an exceptional sensitivity of its MCCs, causing the formation of side-products in the gas-phase not only in the reaction chamber but also during transport. A systematic study might be interesting.

Note that the PFA-TEFLON ${ }^{\circledR}$ tubes of FORA must be assumed to be covered with $\mathrm{H}_{2} \mathrm{O}$ during the entire experiment. Therefore, a clear statement concerning the effect of adsorbed $\mathrm{H}_{2} \mathrm{O}$ can not be made at this point. Also note that the investigated dew point interval during measurements with Miss Piggy differs strongly from the initial measurements with FORA.

\section{Conclusion}

FORA delivers stable investigation conditions for the investigation of the on-line gas phase carbonyl complex formation and transport of single-atom fission products. If given an initial equilibration time of at least $12 \mathrm{~h}$, the addition or removal of gas does not influence the carbonyl formation dramatically, making FORA suitable for investigating, e.g., pressure or gas flow dependencies. Since the system is operated as a gas loop, it can run continuously with a minimum consumption of CO-gas, making FORA especially suitable for measuring time-dependent longterm effects and direct chemical effects induced by a controlled addition of contaminants. For all four elements investigated, Mo, Tc, $\mathrm{Ru}$ and $\mathrm{Rh}$, the reproducibility given identical experimental conditions allows for extended systematic studies.

This study confirmed the addition of oxygen to generally decrease formation and transport yields for all four carbonyl species at rather large concentrations. $\mathrm{Hu}$ midity was shown to be more problematic for the formation yield and compound speciation already at very low concentrations. The impact of air onto MCC formation for Mo and $\mathrm{Ru}$ could be successfully modeled based on the previously obtained data for $\mathrm{O}_{2}$ and $\mathrm{H}_{2} \mathrm{O}$. This confirms that the effect of ambient air entering the system is caused by oxygen and moisture. For Tc and Rh the model indicates a more complex reaction pattern with the partly formation of several volatile species.

Our work demonstrates that mostly the formation of MCC's is influenced by the gas-additives in the carrier gas inside the reaction chamber. Secondary reactions during the transport of the formed MCC's are negligible. From a practical perspective, this means ensuring the highest achievable purity of the process gas at the point of reaction, e.g., by placing purification columns as close to it as possible, should be beneficial.

It must be expected that the heavier elements of the corresponding groups of the periodic table are even more sensitive towards $\mathrm{O}_{2}$ and $\mathrm{H}_{2} \mathrm{O}$ contaminations in the carrier gas, although, e.g., the higher bond stabilities measured for $\mathrm{W}(\mathrm{CO})_{6}$ and predicted for $\mathrm{Sg}(\mathrm{CO})_{6}$ must lead to a higher transport stability of these compounds, once they are formed.

Author contributions: All the authors have accepted responsibility for the entire content of this submitted manuscript and approved submission.

Research funding: This work was supported by the Swiss National Science Foundation (grant 200021_162769).

Conflict of interest statement: The authors declare no conflicts of interest regarding this article.

\section{References}

1. Bhatt V. Essentials of Coordination Chemistry, Chapter 8 Metal Carbonyls, 1st ed.; Elsevier Inc.: Amsterdam, 2015; pp. 191-236.

2. Söderberg B. C. G. Synthesis using transition metal carbonyl complexes. In Encyclopedia of Inorganic and Bioinorganic Chemistry. John Wiley \& sons: Weinheim, 2011, https://doi.org/ 10.1002/9781119951438.eibc0155.

3. Miroslavov A. E., Gorshkov N. I., Lumpov A. L., Yalfimov A. N., Suglobov D. N., Ellis B. L., Braddock R., Smith A. M., Prescott M. C., Lawson R. S., Sharma H. L. Evaluation of ${ }^{99 m} \mathrm{Tc}(\mathrm{CO})_{5} \mathrm{l}$ as a potential lung perfusion agent. Nucl. Med. Biol. 2009, 36, 73-79.

4. Wareham L. K., Poole R. K., Tinajero-Trejo M. CO-releasing metal carbonyl compounds as antimicrobial agents in the postantibiotic era. J. Biol. Chem. 2015, 290, 18999-19007.

5. Schlawe D., Majdalani A., Velcicky J., Heißler E., Wieder T., Prokop A., Schmalz H. G. Eisenhaltige Nucleosidanaloga mit apoptoseinduzierender Wirksamkeit. Angew. Chem. 2004, 116, $1763-1766$.

6. Johnson T. R., Mann B. E., Clark J. E., Foresti R., Green C. J., Motterlini R. Metal carbonyls: a new class of pharmaceuticals? Angew. Chem. Int. Ed. 2003, 42, 3722-3729.

7. Huheey J. E., Keiter E. A., Keiter R. L. Anorganische Chemie Prinzipien von Struktur und Reaktivität, Metallcarbonyle und verwandte Verbindungen, 4th ed.; De Gruyter: Oldenbourg, 2012; pp. 712-734.

8. Calderazzo F. Carbonyl complexes of the transition metals. Encycl. Inorg. Chem., 2006. https://doi.org/10.1002/ $0470862106 . i a 037$.

9. Lukens W. W., Shuh D. K., Schroeder N. C., Ashley K. R. Identification of the non-pertechnetate species in hanford waste tanks, Tc(I)-carbonyl complexes. Environ. Sci. Technol. 2004, 38, 229-233.

10. Even J., Ackermann D., Asai M., Block M., Brand H., Nitto A. D., Düllmann C. E., Eichler R., Fan F., Haba H., Hartmann W., Hübner 
A., Heßberger F. P., Huang M., Jäger E., Kaji D., Kanaya J., Kaneya Y., Khuyagbaatar J., Kindler B., Kratz J. V., Krier J., Kudou Y., Kurz N., Laatiaoui M., Lommel B., Maurer J., Miyashita S., Morimoto K., Morita K., Murakami M., Nagame Y., Nitsche H., Ooe K., Qin Z., Sato T. K., Schädel M., Steiner J., Sumita T., Takeyama M., Tanaka K., Toyoshima A., Tsukada K., Türler A., Usoltsev I., Wakabayashi Y., Wang Y., Wiehl N., Yakushev A., Yamaki S. In situ synthesis of volatile carbonyl complexes with short-lived nuclides. J. Radioanal. Nucl. Chem. 2015, 303, 2457-2466.

11. Wang Y., Qin Z., Fan F. L., Fan F. Y., Cao S. W., Wu X. L., Zhang X., Bai J., Yin X. J., Tian L. L., Zhao L., Tian W., Li Z., Tan C. M., Guo J. S., Gäggeler H. W. Gas-phase chemistry of Mo, Ru, W and Os metal carbonyl complexes. Radiochim. Acta 2014, 102, 69-76.

12. Even J., Yakushev A., Düllmann C. E., Dvorak J., Eichler R., Gothe O., Hild D., Jäger E., Khuyagbaatar J., Kratz J. V., Krier J., Niewisch L., Nitsche H., Pysmenetska I., Schädel M., Schausten B., Türler A., Wiehl N., Wittwer D. Rapid synthesis of radioactive transitionmetal carbonyl complexes at ambient conditions. Inorg. Chem. 2012, 51, 6431-6433.

13. Usoltsev I., Eichler R., Wang Y., Even J., Yakushev A., Haba H., Asai M., Brand H., Nitto A. D., Düllmann C. E., Fangli F., Hartmann W., Huang M., Jäger E., Kaji D., Kanaya J., Kaneya Y., Khuyagbaatar J., Kindler B., Kratz J. V., Krier J., Kudou Y., Kurz N., Lommel B., Miyashita S., Morimoto K., Morita K., Murakami M., Nagame Y., Nitsche H., Ooe K., Sato T. K., Schädel M., Steiner J., Steinegger P., Sumita T., Takeyama M., Tanaka K., Toyoshima A., Tsukada K., Türler A., Wakabayashi Y., Wiehl N., Yamaki S., Qin Z. Decomposition studies of group 6 hexacarbonyl complexes. Part 1: production and decomposition of $\mathrm{Mo}(\mathrm{CO})_{6}$ and $\mathrm{W}(\mathrm{CO})_{6}$. Radiochim. Acta 2016, 104, 141-151.

14. Cao S., Wang Y., Qin Z., Fan F., Haba H., Komori Y., Wu X., Tan C., Zhang X. Gas-phase chemistry of ruthenium and rhodium carbonyl complexes. Phys. Chem. Chem. Phys. 2016, 18, 119-125.

15. Wang Y., Cao S., Zhang J., Fan F., Yang J., Haba H., Komori Y., Yokokita T., Morimoto K., Kaji D., Wittwer Y., Eichler R., Türler A., Qin Z. The study of rhenium pentacarbonyl complexes using single-atom chemistry in the gas phase. Phys. Chem. Chem. Phys. 2019, 21, 7147-7154.

16. Even J., Yakushev A., Düllmann C. E., Haba H., Asai M., Sato T. K., Brand H., Nitto A. D., Eichler R., Fan F. L., Hartmann W., Huang M., Jäger E., Kaji D., Kanaya J., Kaneya Y., Khuyagbaatar J., Kindler B., Kratz J. V., Krier J., Kudou Y., Kurz N., Lommel B., Miyashita S., Morimoto K., Morita K., Murakami M., Nagame Y., Nitsche H., Ooe K., Qin Z., Schädel M., Steiner J., Sumita T., Takeyama M., Tanaka K., Toyoshima A., Tsukada K., Türler A., Usoltsev I., Wakabayashi Y., Wang Y., Wiehl N., Yamaki S. Synthesis and detection of a seaborgium carbonyl complex. Science 2014, 345, 1491-1493.

17. Wang Y., Qin Z., Fan F. L., Haba H., Komori Y., Cao S. W., Wu X. L., Tan C. M. Gas-phase chemistry of technetium carbonyl complexes. Phys. Chem. Chem. Phys. 2015, 17, 13288-13234.

18. Ballof J., Seiffert C., Crepieux B., Ramos J. P., Rothe S., Stora T., Düllmann C. E. Volatile Carbonyl Compounds for New Radioactive Ion Beams at ISOLDE; TASCA17 Conference Abstract: Germany, 2017.

19. Ballof J., Seiffert C., Stora T., Düllmann C. E., Yakushev A. Refractory Beams at ISOLDE - A Concept for a Fission Recoil
Target; 6-th Workshop on Nuclear Fission and Spectroscopy of Neutron-Rich Nuclei: France, 2017; p. 1429.

20. Eichler R. The periodic table - an experimenter's guide to transactinide chemistry. Radiochim. Acta 2019, 107, 865-877.

21. Türler A., Eichler R., Yakushev A. Chemical studies of elements with $Z \geq 104$ in gas phase. Nucl. Phys. 2015, 944, 640-689.

22. Schädel M. Chemistry of the superheavy elements. Phil. Trans. Math. Phys. Eng. Sci. 2015, 373, 1-15.

23. Türler A., Pershina V. Advances in the production and chemistry of the heaviest elements. Chem. Rev. 2013, 113, 1237-1312.

24. Eichler R. First foot prints of chemistry on the shore of the island of superheavy elements. J. Phys. Conf. 2013, 420, 1-17.

25. Loveland W. Superheavy carbonyls. Science 2014, 345, 1451-1452.

26. Eichler R., Asai M., Brand H., Chiera N. M., Nitto A. D., Dressler R., Düllmann C. E., Even J., Fangli F., Goetz M., Haba H., Hartmann W., Jäger E., Kaji D., Kanaya J., Kaneya Y., Khuyagbaatar J., Kindler B., Komori Y., Kraus B., Kratz J. V., Krier J., Kudou Y., Kurz N., Miyashita S., Morimoto K., Morita K., Murakami M., Nagame Y., Ooe K., Piguet D., Sato N., Sato T. K., Steiner J., Steinegger P., Sumita T., Takeyama M., Tanaka K., Tomitsuka T., Toyoshima A., Tsukada K., Türler A., Usoltsev I., Wakabayashi Y., Wang Y., Wiehl N., Wittwer Y., Yakushev A., Yamaki S., Yano S., Yamaki S., Qin Z. Complex chemistry with complex compounds. EPJ Web Conf. 2016, 131, 1-7.

27. Even J., Yakushev A., Düllmann C. E., Dvorak J., Eichler R., Gothe O., Hartmann W., Hild D., Jäger E., Khuyagbaatar J., Kindler B., Kratz J. V., Krier J., Lommel B., Niewisch L., Nitsche H., Pysmenetska I., Schädel M., Schausten B., Türler A., Wiehl N., Wittwer D. In-situ formation, thermal decomposition, and adsorption studies of transition metal carbonyl complexes with short-lived radioisotopes. Radiochim. Acta 2014, 102, 1093-1110.

28. Düllmann C. E., Eichler B., Eichler R., Gäggeler H. W., Jost D. T., Kindler U., Piguet D., Soverna S., Thörle P., Trautmann N., Türler A. Miss Piggy, a californium-252 fission fragment source as a generator of short-lived radionuclides. Nucl. Instrum. Methods Phys. Res. 2003, 512, 595-605.

29. Nucleonica. Database: ENDF/B-VII.1. https://www.nucleonica. com/ (accessed Aug, 2020).

30. Pershina V., Iliaš M. Carbonyl compounds of Tc, Re and Bh: electronic structure, bonding and volatility. J. Chem. Phys. 2018, 149, 204306.

31. Wittwer Y., Eichler R., Zingg R., Herrmann D., Türler A. The influence of gas purification and of macro amounts of metalcarbonyl complexes on the formation of single-atom metalcarbonyl-complexes. Radochim. Acta, submitted.

32. Ehlers A. W., Frenking G., Baerends E. J. Structure and bonding of the noble gas-metal carbonyl complexes $\mathrm{M}(\mathrm{CO})_{5}-\mathrm{Ng}$ $(\mathrm{M}=\mathrm{Cr}, \mathrm{Mo}, \mathrm{W}$ and $\mathrm{ng}=\mathrm{Ar}, \mathrm{Kr}, \mathrm{Xe})$. Organometallics 1997, 16, 4896-4902.

33. Perutz R. N., Turner J. J. Photochemistry of the group 6 hexacarbonyls in low-temperature matrices. III. Interaction of the pentacarbonyls with noble gases and other matrices. J. Am. Chem. Soc. 1975, 97, 4791-4800.

34. Instruments M. Gas correction factors for thermal-based mass flow. www.mksinst.com (accessed Oct, 2019). 
35. Ziegler J. F., Ziegler M. D., Biersack J. P. SRIM - the stopping and range of ions in matter. Nucl. Instrum. Methods Phys. Res. B 2010, 268, 1818-1823.

36. Lopes F. V. S., Grande C. A., Ribeiro A. M., Loureiro J. M., Evaggelos O., Nikolakis V., Rodrigues A. E. Adsorption of $\mathrm{H}_{2}, \mathrm{CO}_{2}$, $\mathrm{CH}_{4}, \mathrm{CO}, \mathrm{N}_{2}$ and $\mathrm{H}_{2} \mathrm{O}$ in activated carbon and zeolite for hydrogen production. Separ. Sci. Technol. 2009, 44, 1045-1073.

37. Bazan R. E., Bastos-Neto M., Moeller A., Dreisbach F., Staudt R. Adsorptionequilibria of $\mathrm{O}_{2}, \mathrm{Ar}, \mathrm{Kr}$ and $\mathrm{Xe}$ on activated carbon and zeolites: single component and mixture data. Adsorption 2011, 17, 371-383.

38. Dreisbach F., Lösch H. W., Harting P. Highest pressure adsorption equilibria data: measurement with magnetic suspension balance and analysis with a new adsorbent/adsorbate-volume. Adsorption 2002, 8, 95-109. https://doi.org/10.1023/a:1020431616093.
39. Iliaš M., Pershina V. Carbonyl compounds of Rh, Ir, and Mt: electronic structure, bonding and volatility. J. Phys. Chem. Chem. Phys. 2020, 22, 18681.

40. Greenwood N. N., Earnshaw A. Chemistry of the Elements, 2nd ed.; Elsevier Ltd.: Amsterdam, 1997.

41. Eichler B., Türler A., Gäggeler H. W. Thermochemical characterization of seaborgium compounds in gas adsorption chromatography. J. Phys. Chem. 1999, 103, 9296-9306.

42. Ltd M. I. Humidity calculator (accessed Dec, 2019).

43. Gibson J. K. High-temperature oxide and hydroxide vapor species of technetium. Radiochim. Acta 1993, 60, 121-126.

Supplementary Material: The online version of this article offers supplementary material (https://doi.org/10.1515/ract-2020-0031). 